\title{
Compressive behaviour and design of prestressed steel elements
}

\author{
Jonathan Gosaye ${ }^{\mathrm{a}, *}$, Leroy Gardner ${ }^{\mathrm{a}}$, M. Ahmer Wadee ${ }^{\mathrm{a}}$, Murray E. Ellen ${ }^{\mathrm{b}}$ \\ ${ }^{a}$ Department of Civil and Environmental Engineering, Imperial College London, London, UK \\ ${ }^{b} S^{2}$, Space Solutions, Sydney, Australia
}

\begin{abstract}
The tensile performance of the chords of steel trusses can be considerably enhanced through the addition of prestressed cables. However, under compression, which may arise due to wind uplift, the prestressing may have a detrimental effect. The behaviour and design of prestressed steel elements in compression is examined presently. Eight experiments on prestressed elements were carried out, where the key variables examined were the initial prestress level, the presence of grout and the member slenderness. Cross-sectional behaviour and member buckling behaviour are examined analytically, numerically and experimentally, with good correlation achieved between the three approaches. The benefit of adding grout to bond the prestressing steel to the encasing tube is also investigated and design approaches for both non-grouted and grouted prestressed elements are proposed.
\end{abstract}

\section{Introduction}

The addition of high tensile cables to conventional steel components can lead to significant material savings, particularly for long span structural systems. Further benefits can be achieved by prestressing the cables to induce internal forces in the structure that can counteract the applied external loads and control self-weight deflections. Prestressing of steel structures has been the subject of a number of investigations. Early work by Magnel [1] in 1950 experimentally demonstrated the improved economy that can be achieved by prestressing truss girders. More recent studies have explored the behaviour and design of prestressed steel beams [2,3], columns $[4,5,6,7,8,9]$, trusses $[10,11]$ and space trusses $[12,13]$. The behaviour of prestressed frames with sliding joints has also been examined both during the stress-erection process [14] and under external loading $[15,16,17,18]$. The above studies have highlighted the potential economies and enhanced performance that can be achieved through the use of prestressing.

The present paper focuses on cable-in-tube systems, in which the prestressing cables are encased within structural hollow sections, with the advantages that the tensile force in the cable will stabilize the surrounding tube against buckling during prestressing and enable the addition of grout, which bonds the two components together to reduce reliance on the end anchorage, as well as increasing compressive strength. Examples of recent applications of such prestressed

\footnotetext{
${ }^{*}$ Corresponding author. Imperial College London, Department of Civil and Environmental Engineering, Skempton Building, Room 428, London SW7 2AZ ; Email: jg607@imperial.ac.uk ; Tel: +447907389916
} 
systems include the reconfiguration of the Sydney Olympic stadium and the Five Star Aviation hangar at Brisbane Airport, both in Australia [19].

In the context of trusses, the tensile performance of the bottom chord can be considerably enhanced through the addition of prestressed cable [20]. However, in instances of load reversal (e.g. due to wind uplift) in trusses without horizontal end anchorage that would allow catenary forces to develop, the presence of prestress could be detrimental. The behaviour and design of prestressed elements subjected to external compression is the subject of the present paper.

Analytical and numerical models that predict the compressive behaviour of the cable-in-tube system are developed in Section 2. Experimental studies are described in Section 3, while comparisons between the test, numerical and analytical results and discussions thereof, are presented in Section 4, followed by design proposals.

\section{Analytical modelling and numerical verification}

In this section, the key behavioural aspects of prestressed elements under compression are described. Firstly, the axial response of the element during the prestressing stage is analysed. The compressive behaviour at the cross-sectional level, considering purely axial deformations, is then examined. Subsequently, member buckling behaviour is introduced with the effect of the addition of grout after prestressing being discussed.

\subsection{Axial response under prestress}

To prestress the cable-in-tube system, a tensile force, $P_{\mathrm{i}}$, is applied to the cable and a compression force of equal magnitude is induced in the tube and the components are locked in position at both ends. Provided the tensioned cable is in contact with the surrounding tube at sufficiently regular intervals with the compressed tube, overall buckling is prevented [20,21] and the equilibrium condition for the prestressed system during the prestressing stage can be stated as:

$$
\left[P_{\mathrm{i}}\right]_{\text {cable }}-\left[P_{\mathrm{i}}\right]_{\text {tube }}=K_{\mathrm{c}} x_{\mathrm{c}}-K_{\mathrm{t}} x_{\mathrm{t}}=0,
$$

where $x_{\mathrm{c}}$ and $x_{\mathrm{t}}$ are the axial displacements during prestress while $K_{\mathrm{c}}$ and $K_{\mathrm{t}}$ are the axial stiffnesses of the cable and the tube respectively. The respective stiffnesses are given by the following expressions:

$$
K_{\mathrm{c}}=\frac{E_{\mathrm{c}} A_{\mathrm{c}}}{L_{\mathrm{o}}}, \quad K_{\mathrm{t}}=\frac{E_{\mathrm{t}} A_{\mathrm{t}}}{L_{\mathrm{o}}},
$$

where $L_{\mathrm{o}}$ is the original length of the system; $E_{\mathrm{c}}$ and $E_{\mathrm{t}}$ are the Young's moduli of the cable and the tube respectively with $A_{\mathrm{c}}$ and $A_{\mathrm{t}}$ being the cross-sectional areas of the cable and the tube respectively.

\subsection{Cross-sectional behaviour of prestressed elements under compression}

The cross-section behaviour of prestressed elements in compression, where member buckling effects are ignored, is first considered. For non-grouted stocky elements in compression, three cases are considered in the following sub-sections: Case I refers to the scenario where the cable slackens before yielding of the tube in compression; Case II refers to the case where the tube 
yields prior to the slackening of the cable; and Case III considers the simultaneous yielding of the tube and slackening of the cable. The case which actually arises depends on the geometric and material properties of the tube and cable, as well as the level of prestress:

$$
\text { Case } \begin{cases}\text { I, } & \text { if } \frac{P_{\mathrm{i}}}{A_{\mathrm{c}} E_{\mathrm{c}}}<\frac{f_{\mathrm{ty}}}{E_{t}}-\frac{P_{\mathrm{i}}}{A_{\mathrm{t}} E_{\mathrm{t}}}, \\ \text { II, } & \text { if } \frac{P_{\mathrm{i}}}{A_{\mathrm{c}} E_{\mathrm{c}}}>\frac{f_{\mathrm{ty}}}{E_{t}}-\frac{P_{\mathrm{i}}}{A_{\mathrm{t}} E_{\mathrm{t}}}, \\ \text { III, } & \text { if } \frac{P_{\mathrm{i}}}{A_{\mathrm{c}} E_{\mathrm{c}}}=\frac{f_{\mathrm{ty}}}{E_{t}}-\frac{P_{\mathrm{i}}}{A_{\mathrm{t}} E_{\mathrm{t}}},\end{cases}
$$

where $f_{\text {cy }}$ and $f_{\text {ty }}$ are the yield stresses of the cable and the tube respectively.

a) Stage 1:

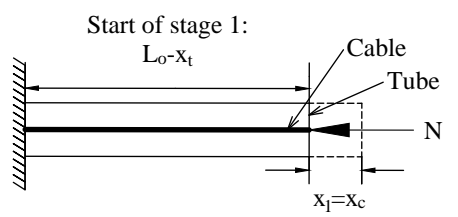

b) Stage 2:

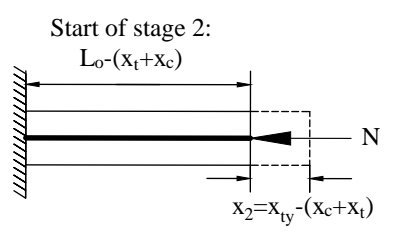

c) Stage 3

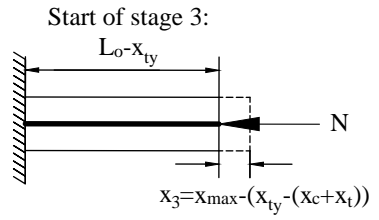

Note: displacements in each stage are expressed with respect to tube deformation.

(a) Case I. a) Stage 1:

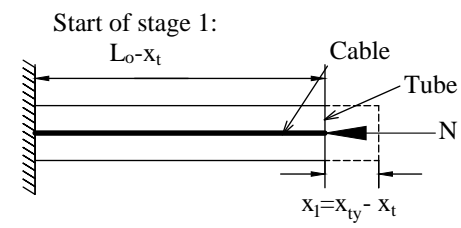

b) Stage 2:
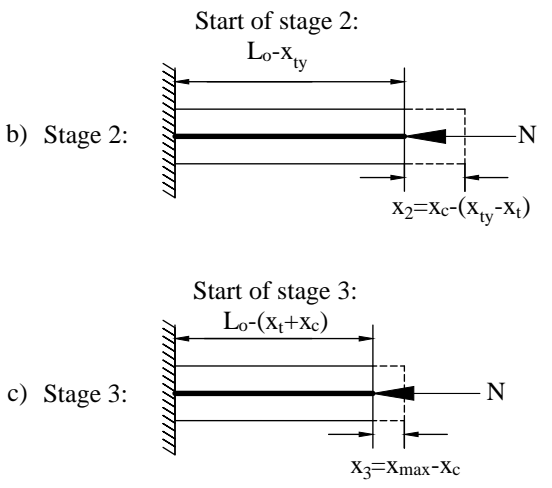

Note: displacements in each stage are expressed with respect to tube deformation.

(b) Case II.

Figure 1: Generalised coordinate definitions for non-grouted stocky elements in compression.

The three stages of behaviour that occur for Case I and Case II are illustrated in Figure 1, where the adopted notation is defined. The corresponding analytical expressions for the loaddisplacement equilibrium path of the system, summarised in Table 1, were derived by following a similar approach as in [20]. In the sign convention adopted, positive values denote compression and shortening whilst negative values denote tension and elongation, with the axial displacement $x_{1}, x_{2}$ and $x_{3}$ being measured from the state of the system at the beginning of each loading stage.

For Case III, initial prestress is applied such that the tube yields and the cable slackens simultaneously under compressive loading. This may be defined as the optimal prestress level since this provides the most extensive elastic range and hence the stiffest response.

The optimal prestress level under applied compressive load, $P_{\mathrm{opt}, \mathrm{c}}$, can be derived by equating the expressions for the strain required to slacken the pretensioned cable to that required to yield the precompressed tube, as shown in Equation (4): 
Table 1: Analytical solution for compressive response of prestressed elements in Case I and Case II.

\section{Case I}

\begin{tabular}{lll}
\hline Stage 1 & Onset of loading until & Onset of loading until \\
& cable slackening: $\left[0 \leqslant x_{1} \leqslant x_{\mathrm{c}}\right]$ & tube yielding: $\left[0 \leqslant x_{1} \leqslant\left(x_{\mathrm{ty}}-x_{\mathrm{t}}\right)\right]$ \\
& $N=\left(K_{\mathrm{c}}+K_{\mathrm{t}}\right) x_{1}$ & $N=\left(K_{\mathrm{c}}+K_{\mathrm{t}}\right) x_{1}$ \\
& $N_{\mathrm{t}}=K_{\mathrm{t}}\left(x_{1}+x_{\mathrm{t}}\right)$ & $N_{\mathrm{t}}=K_{\mathrm{t}}\left(x_{1}+x_{\mathrm{t}}\right)$ \\
& $N_{\mathrm{c}}=K_{\mathrm{c}}\left(x_{1}-x_{\mathrm{c}}\right)$ & $N_{\mathrm{c}}=K_{\mathrm{c}}\left(x_{1}-x_{\mathrm{c}}\right)$ \\
\hline Stage 2 & From cable slackening to tube & From tube yielding to cable \\
& yielding: $\left[0 \leqslant x_{2} \leqslant x_{\mathrm{ty}}-\left(x_{\mathrm{t}}+x_{\mathrm{c}}\right)\right]$ & slackening: $\left[0 \leqslant x_{2} \leqslant x_{\mathrm{c}}-\left(x_{\mathrm{ty}}-x_{\mathrm{t}}\right)\right]$ \\
& $N=K_{\mathrm{t}}\left(x_{\mathrm{t}}+x_{\mathrm{c}}+x_{2}\right)$ & $N=K_{\mathrm{t}} x_{\mathrm{ty}}+K_{\mathrm{c}}\left[x_{2}-x_{\mathrm{c}}+\left(x_{\mathrm{ty}}-x_{\mathrm{t}}\right)\right]$ \\
& & $\quad+K_{\mathrm{st}} x_{2}$ \\
& $N_{\mathrm{t}}=N$ & $N_{\mathrm{t}}=K_{\mathrm{t}} x_{\mathrm{ty}}+K_{\mathrm{st}} x_{2}$ \\
& $N_{\mathrm{c}}=0$ & $N_{\mathrm{c}}=K_{\mathrm{c}}\left[x_{2}-x_{\mathrm{c}}+\left(x_{\mathrm{ty}}-x_{\mathrm{t}}\right)\right]$ \\
\hline Stage 3 & From tube yielding to fracture: & From cable slackening to fracture: \\
& {$\left[0 \leqslant x_{3} \leqslant x_{\mathrm{f}}-\left(x_{\mathrm{ty}}-\left(x_{\mathrm{t}}+x_{\mathrm{c}}\right)\right)\right]$} & {$\left[0 \leqslant x_{3} \leqslant x_{\mathrm{f}}-x_{\mathrm{c}}\right]$} \\
& $N=K_{\mathrm{t}} x_{\mathrm{ty}}+K_{\mathrm{st}} x_{3}$ & $N=K_{\mathrm{t}} x_{\mathrm{ty}}+K_{\mathrm{st}} x_{3}$ \\
& $N_{\mathrm{t}}=N$ & $N_{\mathrm{t}}=N$ \\
& $N_{\mathrm{c}}=0$ & $N_{\mathrm{c}}=0$
\end{tabular}

The formulations of Table 1 can be used to generate axial load-deformation graphs for prestressed elements. Sample analytical results are presented and comparisons are made with corresponding numerical results generated using the FE software ABAQUS [22]. The material and geometrical properties of the different components used in the analytical and numerical models are given in Table 2.

Truss and beam elements with an elastic-perfectly-plastic material model were used to model the tube and prestressing cable, respectively. A tie constraint was applied between the two components for all degrees of freedom except longitudinal displacement along the member length. In the first step of the numerical analysis, prestress was induced through thermal loading of the cable using temperature as a predefined field during a general static analysis. External compressive load was then applied in the following step through displacement control.

Three levels of preload were considered to illustrate the effects of initial prestress levels on the behaviour of the prestressed element under axial compression. The three prestress levels investigated were zero prestress level $\left(P_{0}\right), P_{\mathrm{opt}, \mathrm{c}}$ as calculated from Equation (5) and $P_{\mathrm{opt}, \mathrm{t}}$, which is the optimal prestress corresponding to simultaneous yielding of the tube and cable in 
tension, as defined in [20]. Figure 2 shows the load-displacement response for a prestressed element under various initial prestress levels. The preload forces and displacements, along with the corresponding load-displacement responses for the two components (tube and cable) of the prestressed system, are plotted in Figures 3(a) and (b) for $P_{\mathrm{opt}, \mathrm{c}}$ and $P_{\mathrm{opt}, \mathrm{t}}$ respectively following the sign conventions defined earlier. Good agreement between the numerical and analytical models is observed in both Figures 2 and 3.

For zero prestress level $\left(P_{0}\right)$, Figure 2 shows that the externally applied force is resisted by the compressive strength of the tube until it yields in compression. For $P_{\mathrm{opt}, \mathrm{t}}$, on the other hand, Figure 3(b) shows the tube has an initial compression, which is equilibrated by the initial tensile force of the cable. When an external compressive load is applied to the system, the tube is compressed further and the tensile force in the cable unloads; as a result, the stiffness of the system is the sum of the axial stiffness of the cable and the encasing tube. The tube continues to store elastic compressive strain energy until it yields in compression after which point the tensile force in the cable continues to unload until it slackens at the ultimate load. The relatively large drop in stiffness after tube yielding is due to the high axial stiffness ratio $K_{\mathrm{t}} / K_{\mathrm{c}}=9.2$ for the chosen sections. For prestress level $P_{\text {opt }, \mathrm{c}}$, Figures 2 and 3(a) show that the initial combined stiffness of the system is maintained until the ultimate load, at which point the tube yields and the cable slackens simultaneously. Figure 2 demonstrates that the ultimate compressive strength of a stocky element is independent of initial prestress levels but the addition of an initial prestress beyond $P_{\mathrm{opt}, \mathrm{c}}$ causes earlier yielding of the tube. Moreover, the ultimate load is reached through the unloading of the tensile force within the cable.

Table 2: Properties of prestressed element in the analytical and numerical model.

\begin{tabular}{ll}
\hline Yield strength of tube, $f_{\mathrm{ty}}$ & $355 \mathrm{~N} / \mathrm{mm}^{2}$ \\
Yield strength of cable, $f_{\mathrm{cy}}$ & $1860 \mathrm{~N} / \mathrm{mm}^{2}$ \\
Young's modulus of tube, $E_{\mathrm{t}}$ & $210 \mathrm{kN} / \mathrm{mm}^{2}$ \\
Young's modulus of cable, $E_{\mathrm{c}}$ & $200 \mathrm{kN} / \mathrm{mm}^{2}$ \\
Cross-sectional area of tube, $A_{\mathrm{t}}$ & $879 \mathrm{~mm}^{2}$ \\
Cross-sectional area of cable, $A_{\mathrm{c}}$ & $100 \mathrm{~mm}^{2}$ \\
Coefficient of linear expansion of cable, $\alpha_{\mathrm{c}}$ & $12 \times 10^{-6} \mathrm{~K}^{-1}$ \\
Initial length of tube and cable, $L_{o}$ & $2000 \mathrm{~mm}$ \\
\hline
\end{tabular}

\subsection{Member behaviour of prestressed elements under compression}

A slender prestressed system will fail through the mechanism of instability under external compressive load. The elastic critical load, $N_{\text {cr }}$, and tube yield load, $N_{\text {ty }}$, expressed in Equations (6) and (7), respectively, are the theoretical upper bound estimates of the compression capacity of a prestressed column. The slenderness value and initial prestress level of the cable-in-tube system determines which theoretical upper bound governs. If the slenderness of the cable-intube system is low or if a sufficiently high level of prestress is applied to the system then the tube yield load would be the governing failure load. 


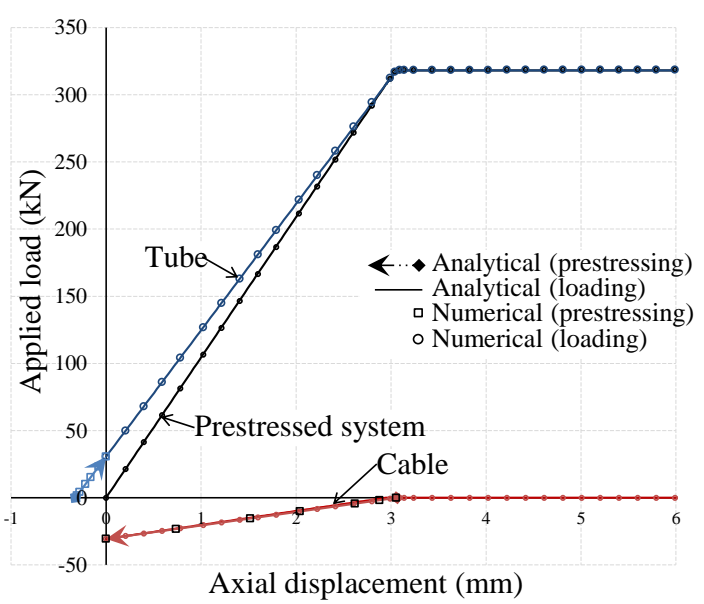

(a) $P_{\text {opt,c }}$ initial prestress.

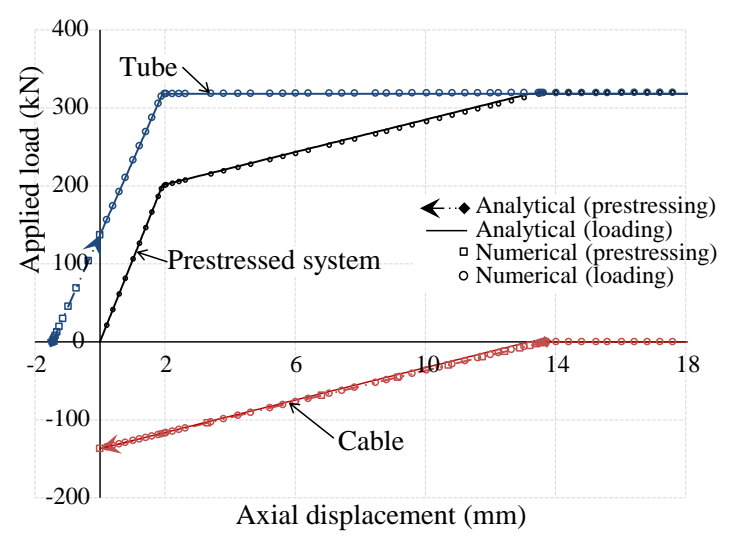

(b) $P_{\text {opt }, \mathrm{t}}$ initial prestress.

Figure 3: Compressive performance of a prestressed element, showing forces in the two component parts of the prestressed system - the tube and cable. 


$$
N_{\text {ty }}=A_{\mathrm{t}} f_{\text {ty }}-P_{\mathrm{i}},
$$

where $I_{\mathrm{t}}$ and $L_{\mathrm{cr}}$ are the second moment of area and the effective buckling length of the encasing tube.

Note that the elastic critical load of the cable-in-tube system is independent of the initial prestress level since, assuming the cable is located at the centre of the tube (i.e. along the neutral axis), which can be enforced through the use of collars [20], it does not induce a disturbing moment when the member deflects laterally. Hence, assuming purely elastic behaviour, the initial prestress level has no impact on the level of external load required to cause buckling of the cable-in-tube system.

To illustrate this point, an elastic numerical model of a cable-in-tube system with varying initial prestress was developed. In the model the elastic material properties of Table 2 were assigned to the components and constraint was applied to the nodes of the prestressing cable and the encasing tube such that their lateral deflection was equal. A nonlinear analysis was performed with an eigenmode affine imperfection (corresponding to the first mode of buckling) of amplitude L/1000 obtained from a prior eigenvalue analysis. In the first step of the nonlinear analysis, prestress was applied through thermal loading of the cable and in the proceeding step a displacement controlled analysis was conducted to apply compression to the cable-in-tube system. The three levels of prestress applied to the system were $P_{0}, 0.5 P_{\mathrm{opt}, \mathrm{t}}$ and $P_{\mathrm{opt}, \mathrm{t}}$; as illustrated in Figure 4 the compressive capacity of the elastic cable-in-tube system is independent of the initial prestress level. The mid-height section moment is also plotted on the secondary vertical axis of Figure 4, where it may be seen to increase linearly with lateral deflection and maintain the same value for a given lateral deflection, regardless of the prestress level; this confirms that no additional second order moment is induced due to the prestress.

Second order elastic and second order rigid-plastic models were used to present the theoretical upper bound solution to the equilibrium path of the prestressed element under compression. The second order elastic response can be described by:

$$
N=N_{\text {cr }}\left(\frac{\omega_{\text {total }}-\omega_{\mathrm{i}}}{\omega_{\text {total }}}\right)
$$

where $\omega_{\text {total }}$ and $\omega_{\mathrm{i}}$ are the lateral deflection at mid-height and the amplitude of the assumed sinusoidal initial imperfection, respectively.

The second order rigid-plastic model assumes that deformations are concentrated at a plastic hinge formed at the mid-height of the prestressed element as shown in Figure 5, where $\omega_{\text {total }}$ is the lateral displacement at mid height. The maximum compressive load that the critical crosssection at the plastic hinge can sustain, which arises when $\omega_{\text {total }}=0$, is equal to the yield load, given with due account for the prestress, by Equation (7). The equilibrium path of the system is determined by considering a fully plastic cross-sectional stress distribution, in which axial load is assumed to be resisted by the central region (C2 in Figure 6) of the cross-section while the two 


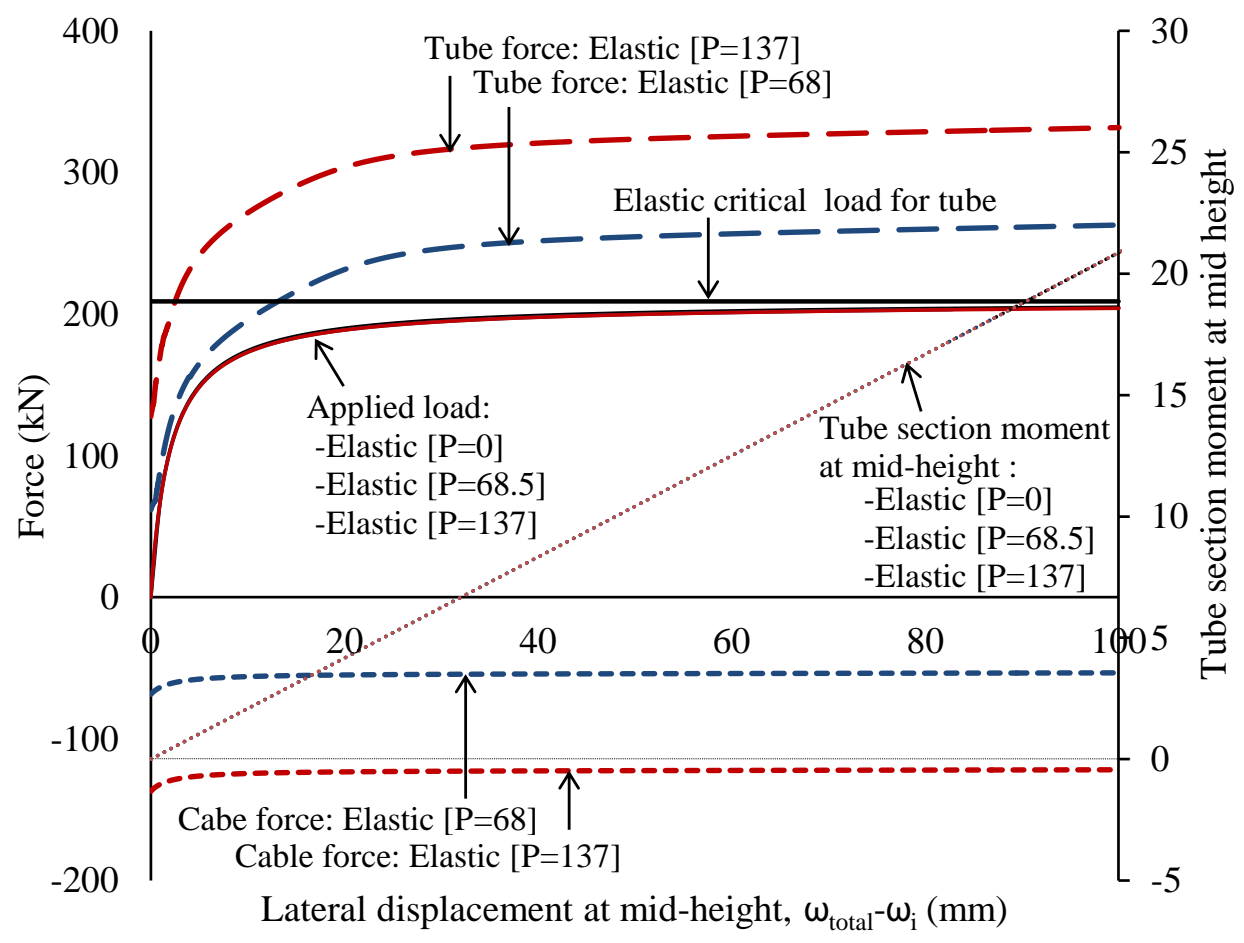

Figure 4: Elastic compressive behaviour of prestressed member. 
outer regions ( $\mathrm{C} 1$ and $\mathrm{T} 1$ in Figure 6, each of depth $\mathrm{c})$ resist the second order moment that arises as the prestressed element deflects laterally.

A lower bound estimate for the ultimate capacity of a prestressed element under compression can be obtained through a modified Perry-Robertson approach. In this approach, the maximum stress at the critical (mid-height) cross-section, $\sigma_{\max }$, in the prestressed element, which is the sum of the axial stress, bending stress and prestress is limited to the yield strength of the material. The maximum strength is given by Equation (9):

$$
\sigma_{\max }=\frac{N}{A_{\mathrm{t}}}+\frac{M d}{I_{\mathrm{t}}}+\frac{P_{\mathrm{i}}}{A_{\mathrm{t}}},
$$

where $M$ and $d$ are the bending moment at mid-height and distance from the neutral axis to the extreme fibres of the tube, respectively. The prestress value $P$ reduces from its initial value $P_{\mathrm{i}}$ under applied compressive loading $N$, following the relationship of Equation 10, which has been derived using equations from Table 1:

$$
P=P_{\mathrm{i}}-\left[\frac{K_{\mathrm{c}}}{K_{\mathrm{c}}+K_{\mathrm{t}}}\right] N .
$$

Following a similar approach to [23], the mean applied stress $\sigma_{\mathrm{b}}=N_{\mathrm{u}, \mathrm{PR}} / A_{\mathrm{t}}$ that causes the concave side of the strut to yield in compression can be expressed as:

$$
\sigma_{\mathrm{b}}=\frac{\left[f_{\mathrm{ty}}+\left(\alpha_{\mathrm{k}}+\eta\right) \sigma_{\mathrm{E}}-\sigma_{\mathrm{P}}\right]}{2 \alpha_{\mathrm{k}}}-\left(\frac{1}{2 \alpha_{\mathrm{k}}}\right) \sqrt{\left[f_{\mathrm{ty}}+\left(\alpha_{\mathrm{k}}+\eta\right) \sigma_{\mathrm{E}}-\sigma_{\mathrm{P}}\right]^{2}-4 \sigma_{\mathrm{E}} \alpha_{\mathrm{k}}\left(f_{\mathrm{ty}}-\sigma_{\mathrm{P}}\right)},
$$

where: 


$$
\begin{gathered}
\alpha_{\mathrm{k}} \begin{cases}=\frac{K_{\mathrm{t}}}{K_{\mathrm{c}}+K_{\mathrm{t}}}, & \text { if } P_{\mathrm{i}}>0, \\
=1, & \text { if } P_{\mathrm{i}}=0,\end{cases} \\
\sigma_{\mathrm{E}}=\frac{\pi^{2}\left(E_{\mathrm{t}} I_{\mathrm{t}}\right)}{A_{\mathrm{t}} L_{\mathrm{o}}^{2}}, \\
\eta=\frac{d A_{\mathrm{t}} \omega_{\mathrm{i}}}{I_{\mathrm{t}}} .
\end{gathered}
$$

Sample analytical results and finite element validation

Sample analytical load-deformation paths and failure loads for slender non-grouted prestressed elements under compression are shown in Figure 7 and Table 3. The results are compared with those from the numerical model discussed earlier in this section, but with the application of the yield criteria given in Table 2. As shown in Figure, 7 the buckling load, $N_{\mathrm{u}, \mathrm{PR}}=\sigma_{\mathrm{b}} A_{\mathrm{t}}$, obtained using Equation (11) accurately predicts the ultimate capacity, $N_{\mathrm{u}, \mathrm{FE}}$, from the numerical model whilst the second order elastic and second order rigid-plastic analyses closely follow the equilibrium path. Figure 7 illustrates that the ultimate compressive strength of the element reduces with increasing prestress levels owing to the fact that slender columns fail through buckling when the extreme fibre of the column yields in compression and the yield point reduces with increasing levels of initially applied prestress.

Table 3: Comparison between numerical and analytical (Perry-Robertson) capacity prediction of prestressed elements in compression.

\begin{tabular}{cccc}
\hline Initial prestress $(\mathrm{kN})$ & $N_{\mathrm{u}, \mathrm{FE}}(\mathrm{kN})$ & $N_{\mathrm{u}, \mathrm{PR}}(\mathrm{kN})$ & $N_{\mathrm{u}, \mathrm{FE}} / N_{\mathrm{u}, \mathrm{PR}}$ \\
\hline$P_{0}$ & 179.1 & 178.5 & 1.00 \\
$0.5 P_{\mathrm{opt}, \mathrm{t}}$ & 167.8 & 166.9 & 1.01 \\
$P_{\mathrm{opt}, \mathrm{t}}$ & 142.2 & 141.4 & 1.01 \\
\hline
\end{tabular}

\section{Experimental Study}

An experimental study was performed in the Structures Laboratory at Imperial College London to verify the analytical and numerical findings for the performance of prestressed cable-intube systems under compressive loads. Material testing, prestressing operations and the compressive member tests are described.

\subsection{Introduction}

A total of 8 cable-in-tube specimens were tested, 3 being non-grouted and 5 being grouted. The key variables of the test programme were the prestress level, the presence of grout and the normalised slenderness. The normalised slenderness for the non-grouted specimens $\bar{\lambda}$ was 


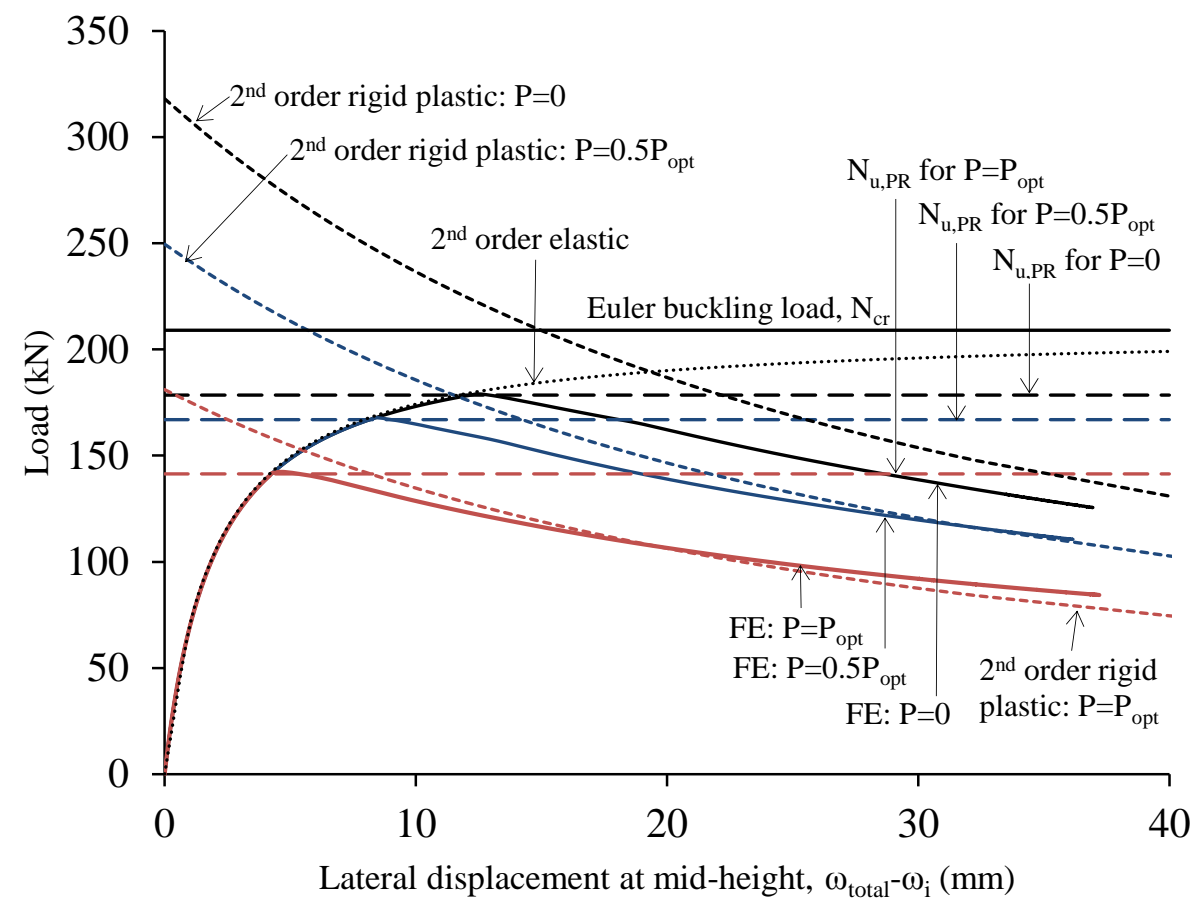

Figure 7: Buckling behaviour of prestressed elements in compression.

calculated as specified in EC3 [24] using properties of the encasing tube, while that for the grouted specimens $\bar{\lambda}_{\mathrm{g}}$ was calculated as specified in EC4 [25]. The cross-section used for all specimens was a cold-formed and seam welded $60 \times 60 \times 4$ square hollow section (SHS) of grade S355 steel. The cables were 7 wire prestressing strands of grade Y1860S7 steel. The adopted test specimen labelling system is explained in Figure 8 and a full list of the test specimens and their properties is given in Table 4. Note that three target prestress levels were considered: $P_{\text {nom }}$, $\frac{1}{2} P_{\mathrm{opt}, \mathrm{t}}$ and $P_{\mathrm{opt}, \mathrm{t}}$ where $P_{\mathrm{nom}}$ is a nominal prestress of about $5 \mathrm{kN}$ to ensure that the cables were not slack during grouting and $P_{\mathrm{opt}, \mathrm{t}}$ is the optimum prestress as described in [20]. The achieved (measured) levels of prestress are given in Table 4 and differ slightly from the target values.

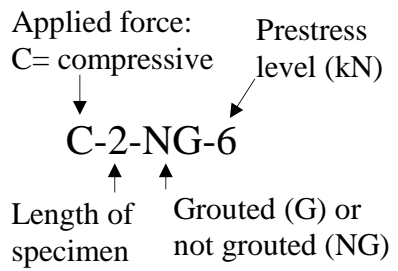

Figure 8: Test specimen labelling system. 
Table 5: Measured weighted average tensile material properties of the tube and cable.

\begin{tabular}{lccccccc}
\hline Component & $E\left(\mathrm{kN} / \mathrm{mm}^{2}\right)$ & $\sigma_{0.2}\left(\mathrm{~N} / \mathrm{mm}^{2}\right)$ & $\sigma_{\mathrm{u}}\left(\mathrm{N} / \mathrm{mm}^{2}\right)$ & $n$ & $n_{0.2, u}^{\prime}$ & $\epsilon_{\mathrm{u}}(\%)$ & $\epsilon_{\mathrm{f}}(\%)$ \\
\hline Tube & 193 & 354 & 408 & 12.0 & 2.0 & 3.2 & 4.1 \\
Cable & 125 & 1775 & 1880 & 10.2 & 1.5 & 3.6 & 3.6 \\
\hline
\end{tabular}

Table 6: Evolution of strength of grout with time.

\begin{tabular}{ccccc}
\hline & 1 day & 3 days & 8 days (Test day) & 28 days \\
\hline Cube strength, $f_{\text {gu }}\left(\mathrm{N} / \mathrm{mm}^{2}\right)$ & 15 & 38 & 55 & 66 \\
\hline
\end{tabular}

\subsection{Preparation of specimens and experimental set-up}

The objective of the experimental programme was to investigate the performance of prestressed cable-in-tube systems under compressive loading. The cold-formed $60 \times 60 \times 4$ SHS tubes were cut to the required length and $20 \mathrm{~mm}$ thick end plates, with holes to allow the prestressing cables to pass through, were welded at both ends of the tube. To prevent buckling of the tubes during the prestressing process, specimens with initial prestress levels higher than the 
nominal prestress level, $P_{\text {nom }}(\sim 5 \mathrm{kN})$, had circular connecting collars fitted to the cables at mid-length and at quarter points, as shown in Figure 9. The circular connecting collars were machined to an external diameter equal to the inside dimension of the SHS and had a central hole to accommodate the cable. The cable, with connecting collars attached at $L_{0} / 4, L_{0} / 2$ and $3 L_{0} / 4$ from the member ends, was then inserted into the tube. The buckling length of the test specimens under preload was therefore approximately one quarter of their full length, as discussed in [20].

Prior to the prestressing of the specimens, the fixed end anchor was seated by applying an initial prestress of $5 \mathrm{kN}$. The prestress was then released to fit a wedge at the stressing end of the specimens. Once both anchors were in place, the specimens were prestressed using a T25 stressing jack. After each specimen was prestressed to the appropriate level, the wedge at the stressing end was hammered to reduce prestress loss due to anchorage slip upon jack removal, as shown in Figure 10. Calibrated strain gauged barrels were used to measure the tensile force in the cable throughout the testing procedures.

Grouting was carried out after prestressing. Specimens that required grouting had holes in the end-plates to allow the grout to flow straight into the tube. Specimens to be grouted were set upright and grout was poured into the specimens at the top end using a funnel. The specimens were tapped, using a metal rod, along the length immediately after the grout was poured to ensure that the grout had filled the tube completely.

After the prestressing process, the specimens were tested under axial loading using the experimental configuration depicted in Figure 11(a). Pinned end conditions were achieved by means of hardened steel knife-edges. To affix the knife-edges to the specimens, encasing cylinders (with a $120 \mathrm{~mm}$ bolt circle diameter, $20 \mathrm{~mm}$ thickness and $100 \mathrm{~mm}$ length) were bolted on to the end plates in order to house the cable anchorage, as shown in 11(c).

For specimens with a global imperfection of less than $L_{0} / 1000$, the bolt positions of the knifeedges were adjusted to apply eccentricity such that the combined imperfection and eccentricity was $L_{0} / 1000$. As illustrated in Figure 11(a), a string pot was attached at the mid-height of the column to measure lateral deflection and strain gauges were affixed at the centre of each face of the SHS tube.

Compressive loading was applied to the specimens at a rate of $0.25 \mathrm{~mm} / \mathrm{s}$ using an Instron 400 HVL machine. The data acquisition equipment DATASCAN was used to recored the load, strain and displacement measurements while the data was logged using the DSLOG software.

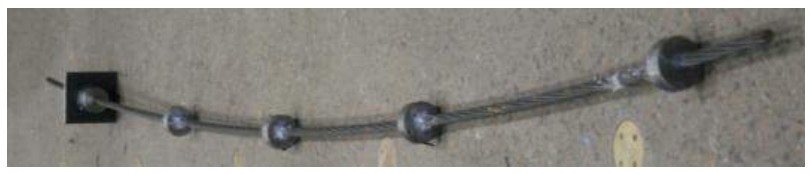

Figure 9: Cable and connecting collar arrangement.

The cable used in all specimens was cut from a coil of 7 wire strand cable with an average cross-sectional area, $A_{\mathrm{c}}$, of $107.1 \mathrm{~mm}^{2}$. A summary of the geometric properties of the test specimens is shown in Table 7, where $L_{0}$ is the specimen length between the knife edges prior to prestress application, $b$ and $h$ are the outer width and height of the SHS specimens, $t$ is the material thickness, $r_{\mathrm{i}}$ is the internal corner radius and $\omega_{\mathrm{i}}$ is the global imperfection at the mid- 


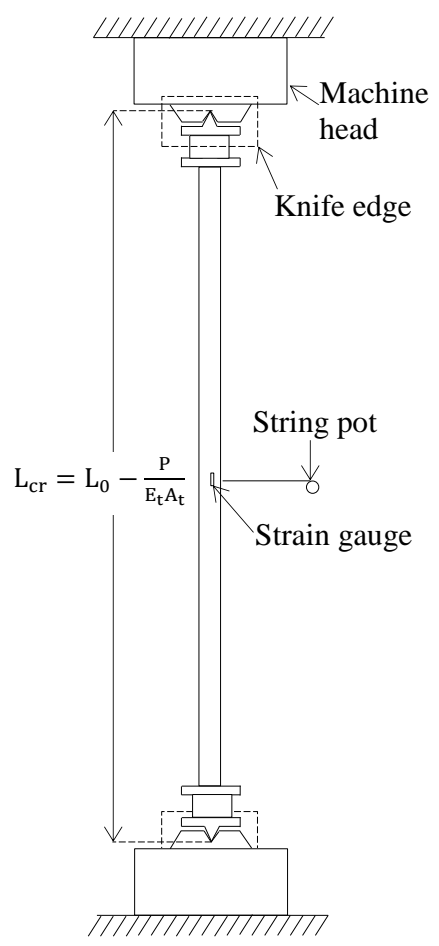

(a) Schematic setup

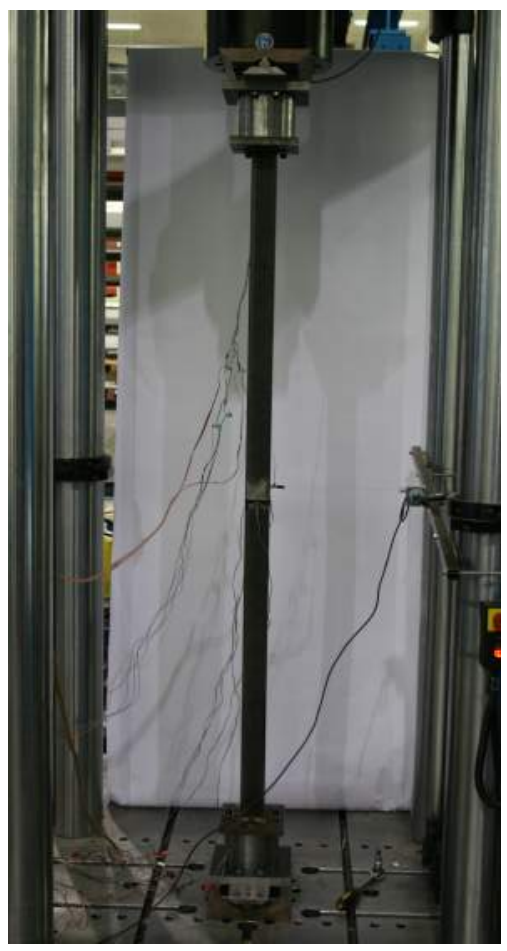

(b) Experimental setup

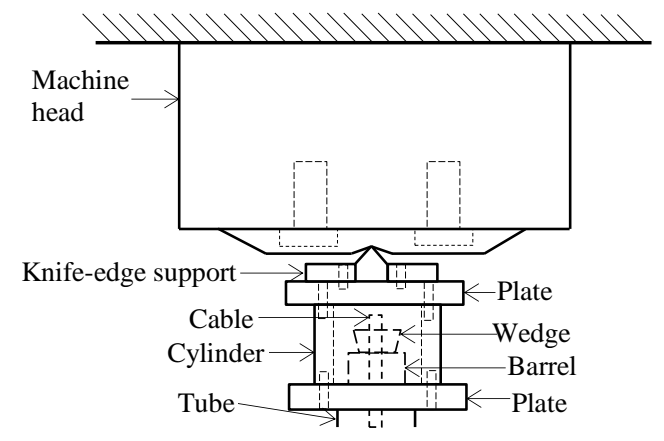

(c) Knife-edge detail.

Figure 11: Prestressed specimen compression test arrangement. 
height of the column.

Table 7: Summary of measured properties of cable-in-tube test specimens.

\begin{tabular}{lcccccc}
\hline Specimen & $L_{0}(\mathrm{~mm})$ & $b(\mathrm{~mm})$ & $h(\mathrm{~mm})$ & $t(\mathrm{~mm})$ & $r_{\mathrm{i}}(\mathrm{mm})$ & $\omega_{\mathrm{i}}(\mathrm{mm})$ \\
\hline C-2-NG-6 & 1997 & 60.1 & 59.7 & 3.90 & 2.0 & 1.0 \\
C-2-NG-60 & 1998 & 60.2 & 60.1 & 3.84 & 2.0 & 1.0 \\
C-2-NG-122 & 1998 & 60.0 & 59.9 & 3.93 & 2.0 & 1.0 \\
C-2-G-11 & 1998 & 59.8 & 59.9 & 3.83 & 2.0 & 1.4 \\
C-2-G-90 & 1998 & 59.9 & 60.2 & 3.91 & 2.0 & 0.6 \\
C-2-G-126 & 1998 & 59.9 & 59.8 & 3.93 & 2.0 & 0.3 \\
C-1-G-10 & 999 & 60.1 & 60.0 & 3.84 & 2.0 & 0.4 \\
C-1-G-75 & 999 & 60.1 & 60.0 & 3.92 & 2.0 & 0.2 \\
\hline
\end{tabular}

\subsection{Experimental results}

The full set of experimental results are shown in Figure 12, which gives the compressive load-lateral deflection response of the eight specimens. The figure illustrates that the test specimens exhibit the characteristic behaviour predicted by the analytical model discussed in Section 2 , whereby the increase in the level of prestress up to $P_{\mathrm{opt}, \mathrm{t}}$ reduces the compressive capacity of the cable-in-tube system. However, the compression due to the prestress is not as detrimental as that due to the applied load since the prestressing force remains as a uniform axial load on the tube, without inducing second order bending moments as the member deflects laterally under load. The results for grouted specimens exhibit similar patterns of behaviour to their non-grouted counterparts in that increasing prestress level reduces the capacity of the specimen; however, the addition of grout significantly enhances the compressive capacity of the members.

\section{Comparison between experimental data, 3D FE results and design predictions}

In this section, the experimental results are assessed in more detail and comparisons are made with 3D finite element (FE) results and design predictions. The design predictions were formulated on the basis of the modified Perry-Robertson approach presented earlier. Material and geometrical properties of the components of the 3D FE and analytical models were defined using the measured values reported in Section 3.2 and Tables 7 and 4. The respective measured $0.2 \%$ proof stress values, $\sigma_{0.2}$, were used for the yield strength of the tube $f_{\text {ty }}$ and cable $f_{\text {cy }}$ in the analytical model. A detailed description of the material models and the modelling techniques used in the FE analysis are outlined in Section 4.1. Note that the 3D FE models presented in this section are initially employed to replicate accurately the observed experimental behavior of both the non-grouted and grouted specimens, after which additional parametric results are generated.

\subsection{Finite element modelling}

The components of the numerical model were the SHS tube, the prestressing cable, the connecting collars and the confined grout for the grouted specimens. Since the cross-section 


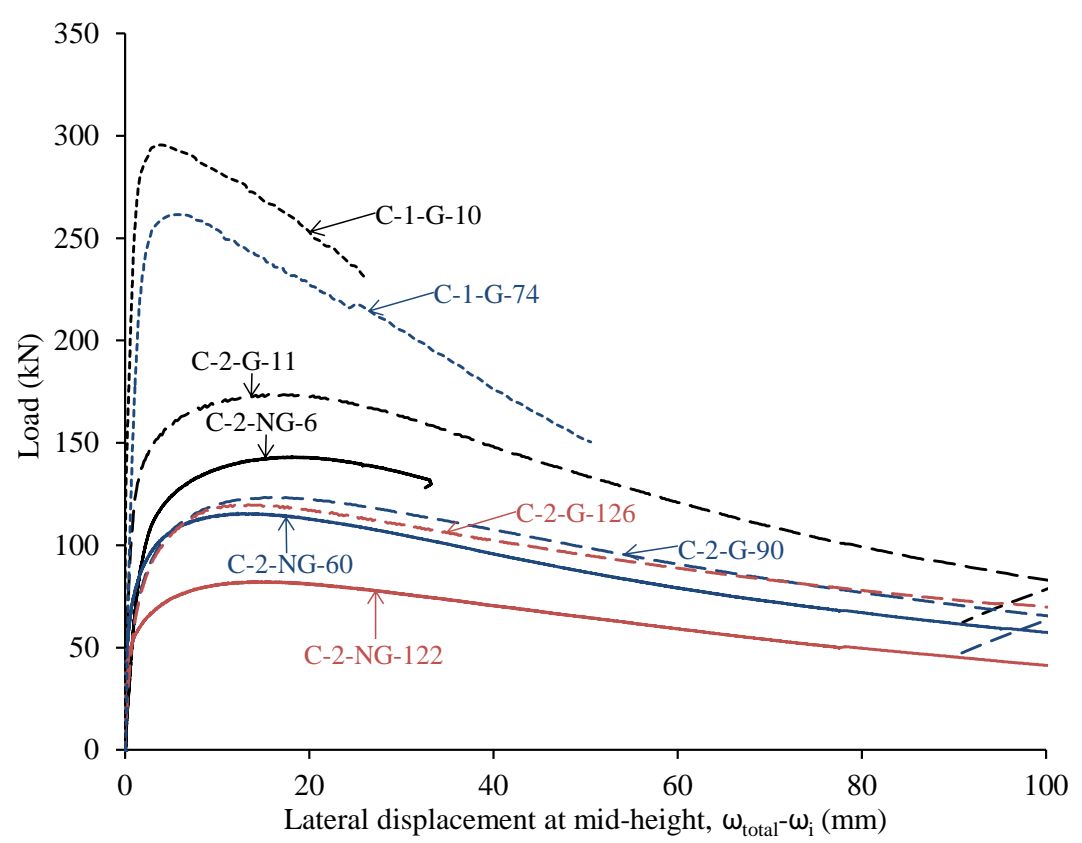

Figure 12: Load-lateral displacement response for all grouted and non-grouted test specimens.

of the encasing tube was compact, and for improved numerical stability, a fine mesh of threedimensional eight node (C3D8) solid elements were used to model all of the components. The mesh size reported in [27] was adopted herein.

\subsubsection{Boundary conditions and load application}

Owing to symmetry, only half of the column cross-section was modelled with the symmetry surface prevented from displacing in the perpendicular direction. As before, an initial imperfection in the form of the first eigenmode and of the amplitudes reported in Table 7 was assigned to the models. In the first loading step of the nonlinear analysis, prestress was applied to the cable through thermal loading. In the numerical model of the grouted specimens, the grout was initially made to be shorter than the encasing tube, since in reality the grout is added after the prestressing stage. The grout was tied to the end plate at one end and the gap between the end plate and the grout closes at the end of the prestressing stage. Displacement control was then employed in the proceeding step of the numerical analysis to apply compression to the cable-in-tube system.

\subsubsection{Material modelling}

The two stage Ramberg-Osgood model using the measured stress-strain responses of the cable and tube, reported in Table 5 was adopted in the 3D FE model. Residual stresses are induced in steel members through non-uniform cooling and as a result of plastic deformation. In the case of cold-formed tubular sections, the dominant residual stresses are in the form of through-thickness bending [28, 29]. Provided the material coupons, which curve longitudinally upon extraction from the sections as a result of these residual stresses, are not straightened by plastic deformation prior to testing, then their influence will be inherently present in the recorded 
stress-strain properties [30]. This was the case in the present study, and hence it was not necessary to explicitly add residual stresses into the FE models. The grout was modelled using the measured cube strength $f_{\text {gu }}$, reported in Table 6 , in conjunction with the uniaxial compressive stress-strain curve developed in [27, 31, 32, 33] for confined concrete. The tensile failure stress, $f_{\mathrm{gt}}$, was defined using the method proposed in [34] as a function of the cube strength. The fracture energy per unit area, $G_{\mathrm{f}}$, was assumed to be $0.12 \mathrm{~N} / \mathrm{mm}$, as recommended by CEB [35]. A linear post-peak softening uniaxial tensile stress-strain curve was defined using the tensile strength, $f_{\mathrm{gt}}$, and fracture energy, $G_{\mathrm{f}}$. The concrete damage plasticity model in ABAQUS [22] was used to implement the uniaxial compressive and tensile stress-strain relationships.

\subsubsection{Steel-grout interface}

For numerical modelling of the grouted members, a friction coefficient of 0.25 was used to define the tangential behaviour of the contact faces of the tube-grout and grout-cable interface elements. The contact surfaces were restricted from penetrating each other but were allowed to separate under tensile forces.

\subsubsection{Validation and parametric study}

Comparisons between the test results and those obtained from 3D FE models are presented in Sections 4.2 and 4.3 for the non-grouted and grouted specimens respectively. The comparisons will show that the FE models are able to capture accurately the observed physical behaviour, the load-deformation history of the prestressed members, including the load-sharing between the constituent elements, and the ultimate load-carrying capacity. Following validation of the models, parametric results are generated for a range of slenderness values and prestress levels, which are used for the development and assessment of design proposals in Section 4.4.

\subsection{Non-grouted specimen results}

The experimental load-displacement curves for the non-grouted specimens, together with the corresponding analytical and 3D FE results are shown in Figures 13-15. In general, there is close agreement between the theoretical and experimental results. The ultimate test loads $N_{\mathrm{u} \text {,test }}$ are reported in Table 8, where they are compared to the numerical values $N_{\mathrm{u}, \mathrm{FE}}$ as well as predicted design values $N_{\text {u,calc }}$ using the method discussed in Section 4.4. Overall, the test ultimate load was well predicted by the FE models, with an average ratio of $N_{\mathrm{u}, \text { test }} / N_{\mathrm{u}, \mathrm{FE}}$ of 0.97 .

Figure 13 shows the results for specimen C-2-NG-6. There is good agreement between the experimental, FE and analytical results. A maximum compressive capacity of $143 \mathrm{kN}$ was achieved in the test, and as this specimen only had a nominal prestress level, its performance shall be used as the benchmark in the following discussion. The experimental results for specimen C-2-NG-60 are shown in Figure 14 and are in very close agreement with the analytical and FE results. From the axial force variation plotted for the tube and cable in Figure 14, it is observed that minimal reduction occurs in the initial prestress level of the cable throughout the loading stage. The figure also shows that the tube is subjected to a greater level of axial force than the applied load since it also has to equilibrate the tensile force of the prestressed cable. In comparison to specimen C-2-NG-6, the addition of about $60 \mathrm{kN}$ of prestress in specimen C2-NG-60 reduced the capacity of the system by about $30 \mathrm{kN}$, corresponding to approximately $20 \%$. 
The highest prestress level for non-grouted elements was applied to specimen C-2-NG-122, the results of which are shown in Figure 15. Again, there is a very close agreement between the experimental, FE and analytical results. Similar to specimen C-2-NG-60, a gradual reduction in initial prestress level was observed during the loading stage. Compared to specimen C-2-NG-6, the addition of about $120 \mathrm{kN}$ of initial prestress in specimen C-2-NG-122 caused a reduction compressive capacity of the cable-in-tube system of about $60 \mathrm{kN}$, corresponding to about $40 \%$.

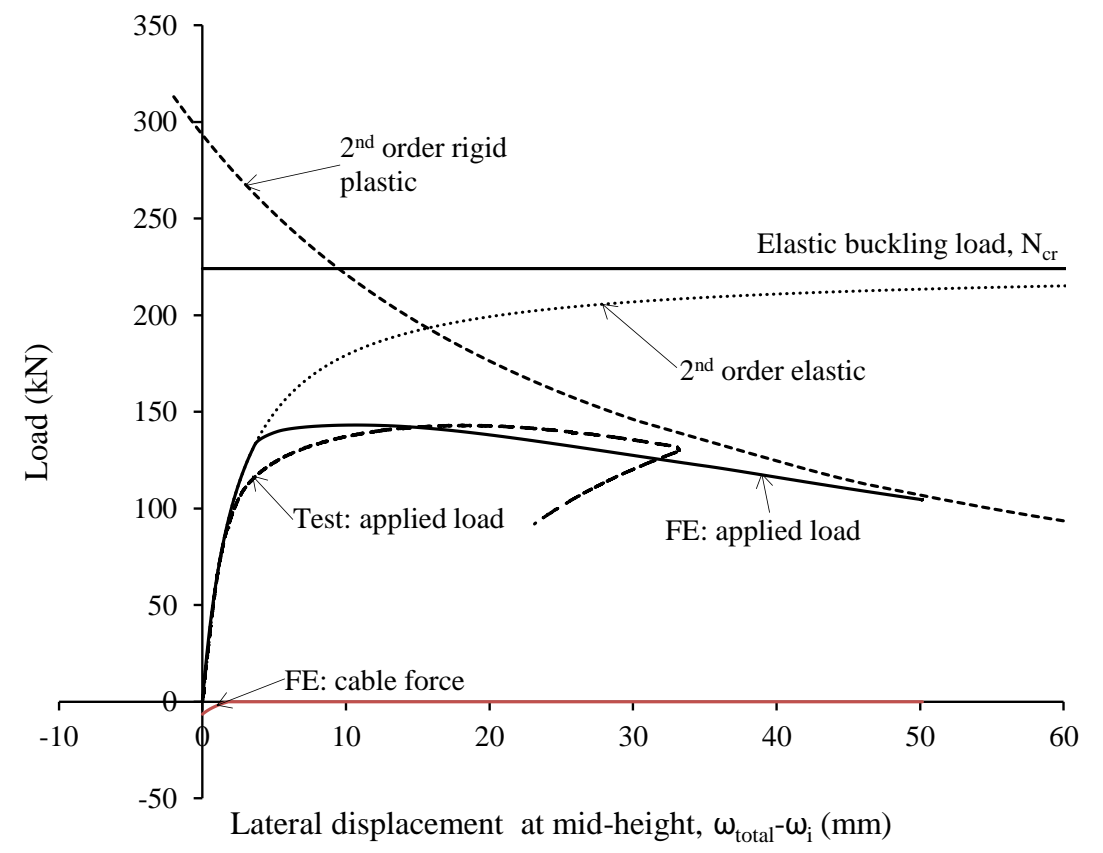

Figure 13: Comparison between experimental, analytical and FE results for specimen C-2-NG-6.

\subsection{Grouted specimen results}

The load-deflection responses of the grouted specimens are shown in Figures 16 to 20. Overall, the level of initial prestress had similar effects on the performance of the grouted specimens as on the non-grouted specimens, but the addition of the grout resulted in increased compressive strength. From the comparisons presented in Table 9, it may be seen that the ultimate test loads were generally fairly well replicated by the FE models, with a mean test to FE ultimate load ratio $\left(N_{\mathrm{u}, \text { test }} / N_{\mathrm{u}, \mathrm{FE}}\right)$ of 0.93 .

\subsection{Design recommendations and comparison with test and $3 D F E$ resullts}

\subsubsection{Design approach}

As discussed earlier in Section 2.3, the Perry-Robertson approach can be adopted to include the effects of initial prestress on the buckling load of non-grouted cable-in-tube systems and it has been shown in Figure 7 and Table 3 to provide accurate strength predictions when compared to numerical results on prestressed elements with elastic, perfectly plastic material behaviour. 


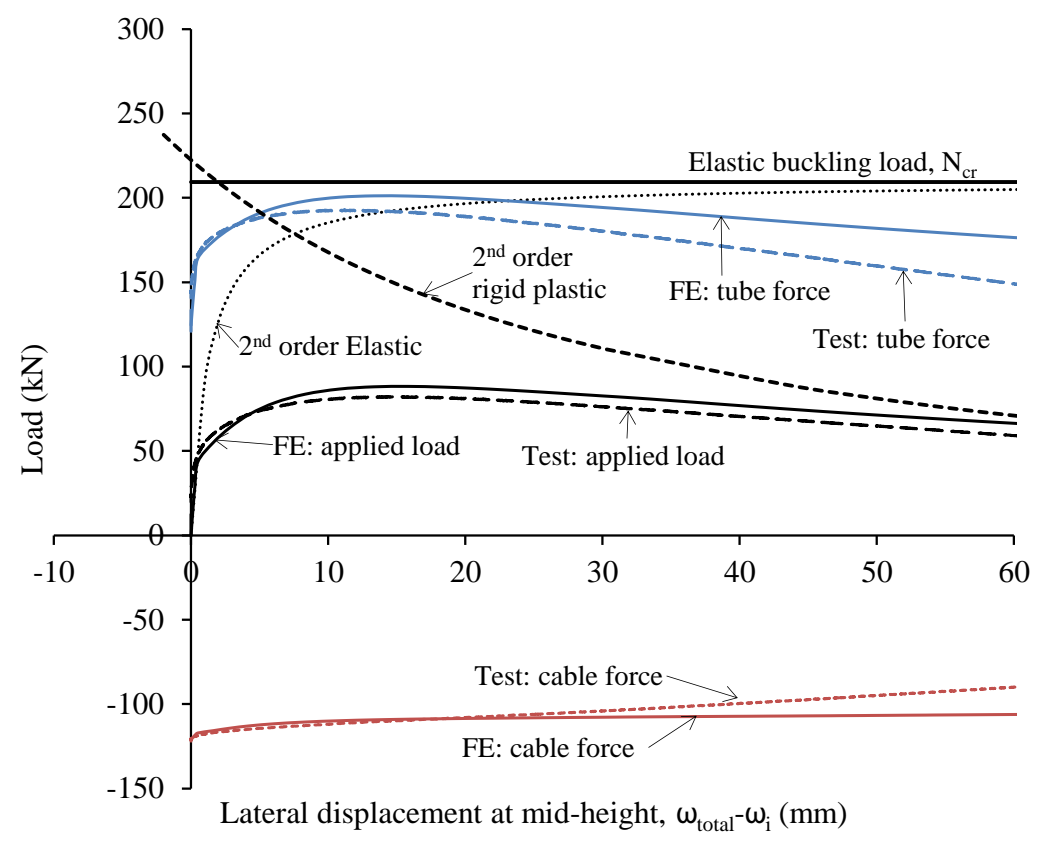

Figure 15: Comparison between experimental, analytical and FE results for specimen C-2-NG-122. 
Table 8: Comparison of ultimate compressive load obtained from experiments, FE and proposed design model for non-grouted specimens.

\begin{tabular}{lccccccc}
\hline Specimen & $\begin{array}{c}N_{\mathrm{u}, \text { test }} \\
(\mathrm{kN})\end{array}$ & $\begin{array}{c}N_{\mathrm{u}, \mathrm{FE}} \\
(\mathrm{kN})\end{array}$ & $\begin{array}{c}\text { Buckling } \\
\text { curve }\end{array}$ & $\begin{array}{c}N_{\mathrm{u}, \text { calc }} \\
(\mathrm{kN})\end{array}$ & $\begin{array}{c}\frac{N_{\mathrm{u}, \text { test }}}{N_{\mathrm{u}, \mathrm{FE}}} \\
\text { C-2-NG-6 }\end{array}$ & $\begin{array}{c}N_{\mathrm{u}, \text { test }} \\
N_{\mathrm{u}, \text { calc }}\end{array}$ & $\frac{N_{\mathrm{u}, \mathrm{FE}}}{N_{\mathrm{u}, \text { calc }}}$ \\
C-2-NG-60 & 143.3 & 143.2 & $\mathrm{c}$ & 132.3 & 1.00 & 1.08 & 1.08 \\
C-2-NG-122 & 82.3 & 88.3 & $\mathrm{~d}$ & 79.1 & 0.93 & 1.04 & 1.12 \\
\hline C-0.8-NG-6-FE & - & 272.5 & $\mathrm{c}$ & 251.9 & - & - & 1.08 \\
C-0.8-NG-60-FE & - & 229.3 & $\mathrm{c}$ & 219.5 & - & - & 1.04 \\
C-0.8-NG-122-FE & - & 181.8 & $\mathrm{~d}$ & 153.0 & - & - & 1.19 \\
C-1.7-NG-6-FE & - & 164.6 & $\mathrm{c}$ & 161.8 & - & - & 1.02 \\
C-1.7-NG-60-FE & - & 139.6 & $\mathrm{c}$ & 144.6 & - & - & 0.97 \\
C-1.7-NG-122-FE & - & 108.1 & $\mathrm{~d}$ & 99.2 & - & - & 1.09 \\
C-2.5-NG-6-FE & - & 105.8 & $\mathrm{c}$ & 94.8 & - & - & 1.12 \\
C-2.5-NG-60-FE & - & 89.9 & $\mathrm{c}$ & 88.0 & - & - & 1.02 \\
C-2.5-NG-122-FE & - & 67.7 & $\mathrm{~d}$ & 64.6 & - & - & 1.05 \\
C-3.4-NG-6-FE & - & 66.6 & $\mathrm{c}$ & 59.3 & - & - & 1.12 \\
C-3.4-NG-60-FE & - & 60.6 & $\mathrm{c}$ & 56.2 & - & - & 1.08 \\
C-3.4-NG-122-FE & - & 45.7 & $\mathrm{~d}$ & 43.7 & - & - & 1.04 \\
\hline & & & & Mean & 0.97 & 1.03 & 1.07 \\
& & & & COV & 0.03 & 0.05 & 0.05
\end{tabular}

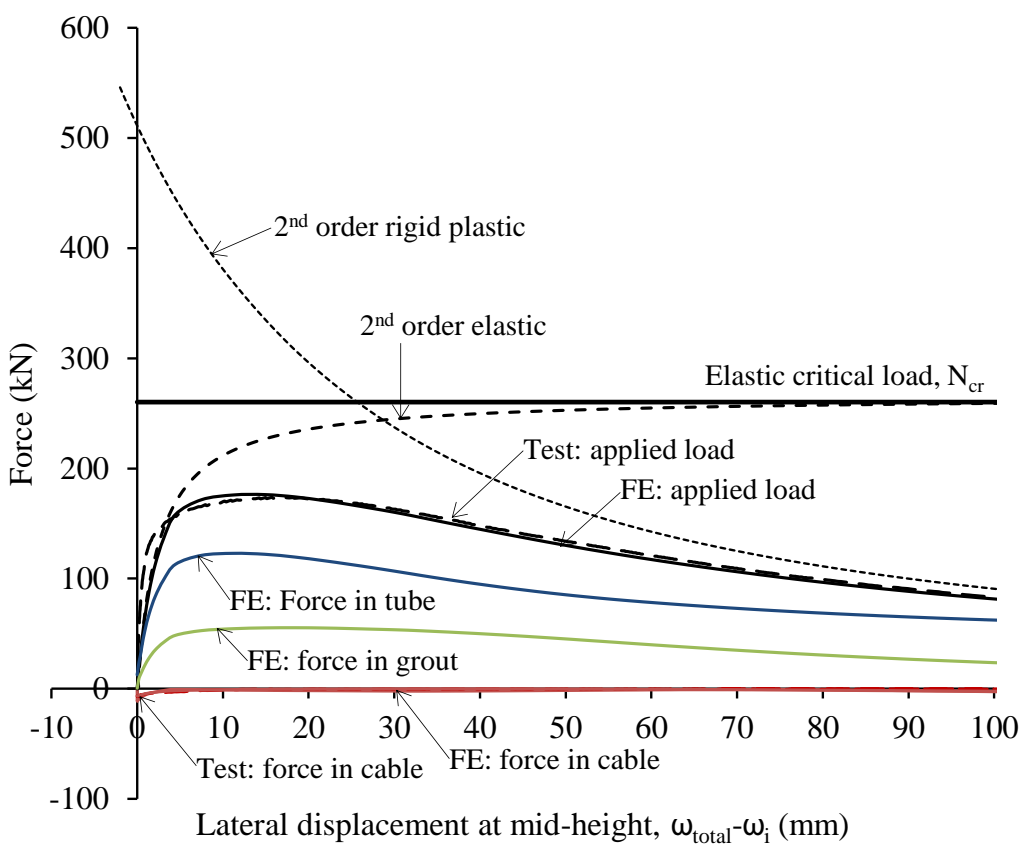

Figure 16: Comparison between experimental, analytical and FE results for specimen C-2-G-11. 
Figure 17: Comparison between experimental, analytical and FE results for specimen C-2-G-90.

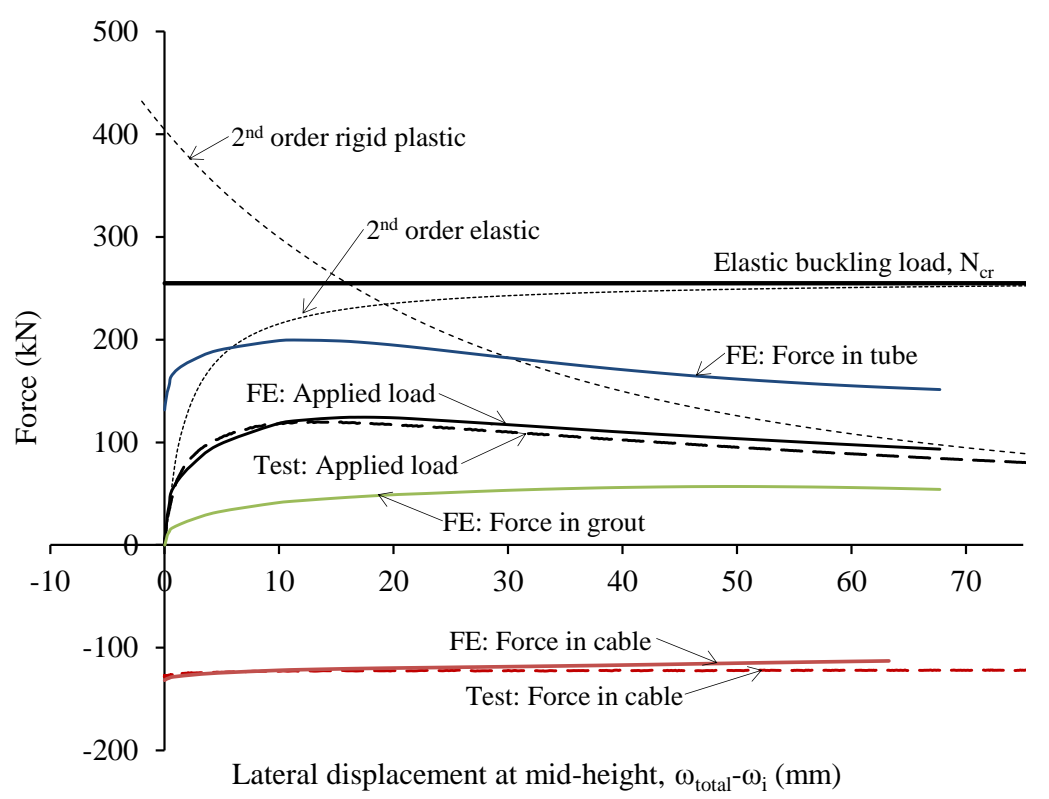

Figure 18: Comparison between experimental, analytical and FE results for specimen C-2-G-126. 


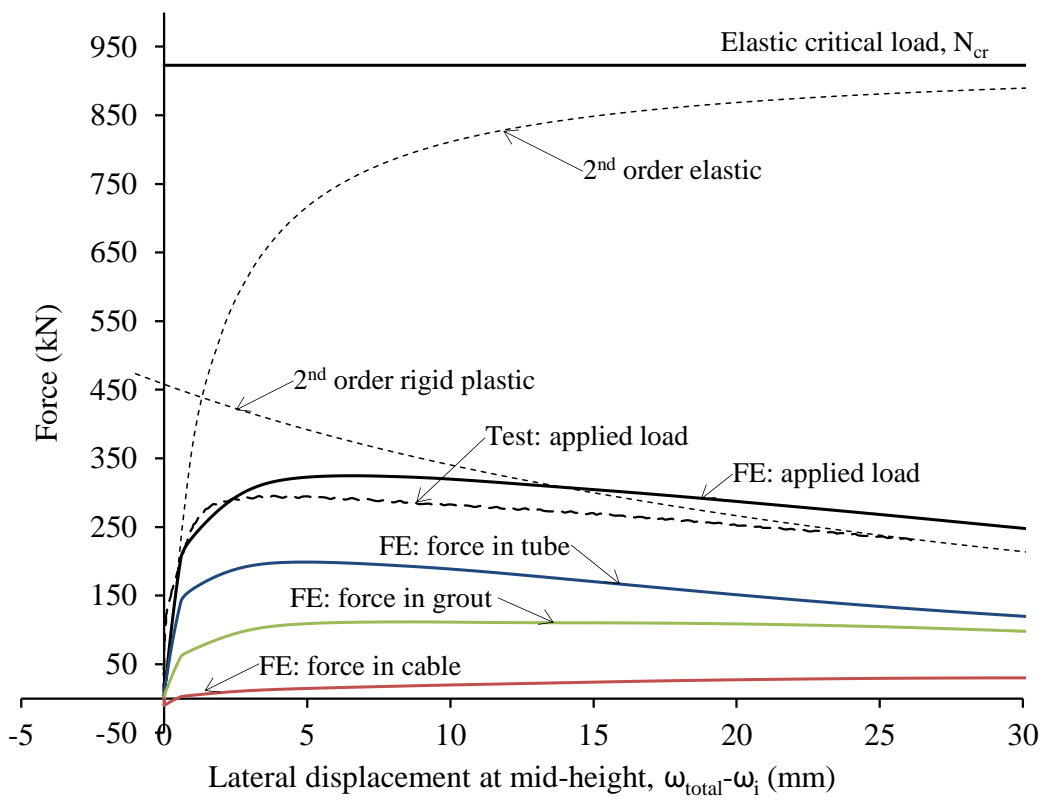

Figure 19: Comparison between experimental, analytical and FE results for specimen C-1-G-10.

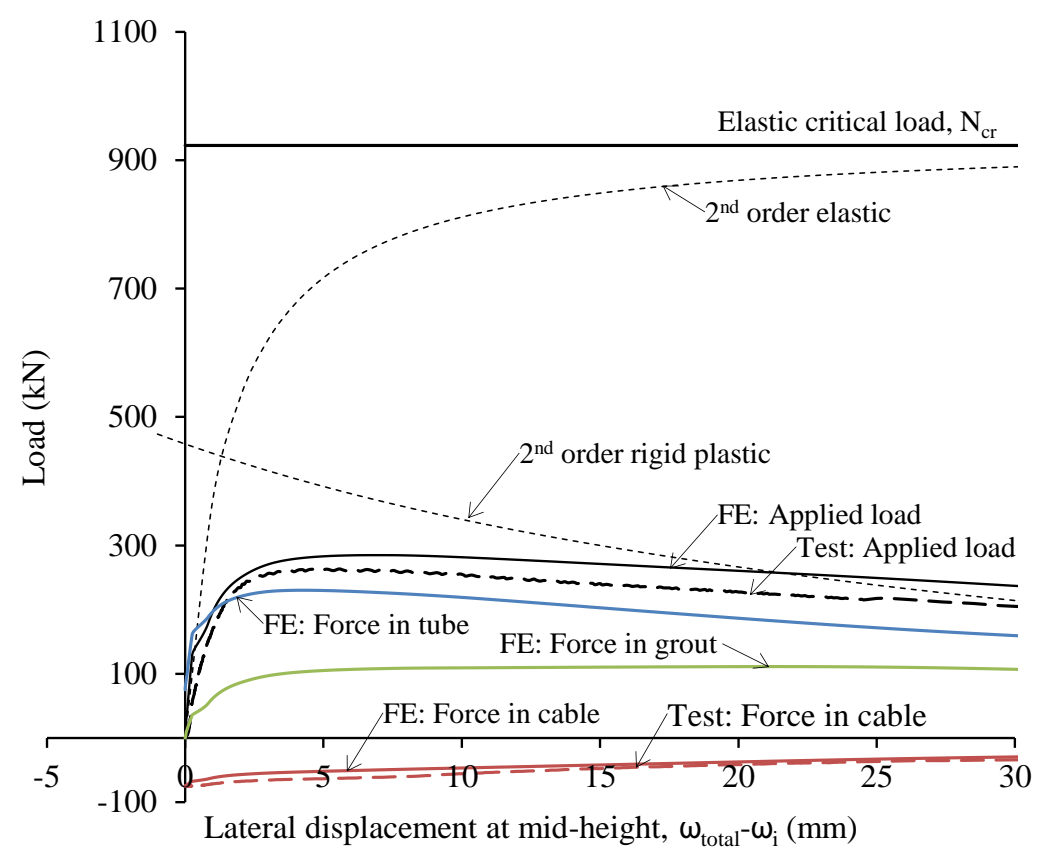

Figure 20: Comparison between experimental, analytical and FE results for specimen C-1-G-75. 
Table 9: Comparison of ultimate compressive load obtained from experiments, FE and proposed design model for grouted specimens.

\begin{tabular}{|c|c|c|c|c|c|c|c|}
\hline Specimen & $\begin{array}{c}N_{\mathrm{u}, \text { test }} \\
(\mathrm{kN})\end{array}$ & $\begin{array}{c}N_{\mathrm{u}, \mathrm{FE}} \\
(\mathrm{kN})\end{array}$ & $\begin{array}{c}\text { Buckling } \\
\text { curve }\end{array}$ & $\begin{array}{c}N_{\mathrm{u}, \text { calc }} \\
(\mathrm{kN})\end{array}$ & $\frac{N_{\mathrm{u}, \text { test }}}{N_{\mathrm{u}, \mathrm{FE}}}$ & $\frac{N_{\mathrm{u}, \text { test }}}{N_{\mathrm{u}, \text { calc }}}$ & $\frac{N_{\mathrm{u}, \mathrm{FE}}}{N_{\mathrm{u}, \mathrm{calc}}}$ \\
\hline C-2-G-11 & 173.8 & 176.3 & $\mathrm{c}$ & 160.2 & 0.99 & 1.09 & 1.10 \\
\hline C-2-G-90 & 123.4 & 141.9 & $\mathrm{c}$ & 123.4 & 0.87 & 1.00 & 1.15 \\
\hline C-2-G-126 & 120.1 & 124.4 & d & 115.4 & 0.97 & 1.04 & 1.08 \\
\hline C-1-G-10 & 295.5 & 324.6 & $\mathrm{c}$ & 312.7 & 0.91 & 0.94 & 1.04 \\
\hline C-1-G-74 & 263.3 & 284.8 & $\mathrm{c}$ & 269.5 & 0.92 & 0.98 & 1.06 \\
\hline C-0.8-G-11-FE & - & 413.2 & $\mathrm{c}$ & 346.4 & - & - & 1.19 \\
\hline C-0.8-G-90-FE & - & 348.8 & $\mathrm{c}$ & 273.2 & - & - & 1.28 \\
\hline C-0.8-G-126-FE & - & 307.6 & $\mathrm{~d}$ & 244.6 & - & - & 1.26 \\
\hline C-1.5-G-11-FE & - & 251.1 & $\mathrm{c}$ & 223.2 & - & - & 1.12 \\
\hline C-1.5-G-90-FE & - & 199.8 & c & 169.0 & - & - & 1.18 \\
\hline C-1.5-G-126-FE & - & 179.5 & d & 155.0 & - & - & 1.16 \\
\hline C-2.3-G-11-FE & - & 151.3 & $\mathrm{c}$ & 131.2 & - & - & 1.15 \\
\hline C-2.3-G-90-FE & - & 119.2 & $\mathrm{c}$ & 104.4 & - & - & 1.14 \\
\hline C-2.3-G-126-FE & - & 104.2 & $\mathrm{~d}$ & 98.0 & - & - & 1.06 \\
\hline C-3.1-G-11-FE & - & 94.4 & $\mathrm{c}$ & 82.2 & - & - & 1.15 \\
\hline C-3.1-G-90-FE & - & 78.3 & $\mathrm{c}$ & 68.5 & - & - & 1.14 \\
\hline \multirow[t]{3}{*}{ C-3.1-G-126-FE } & - & 67.2 & d & 65.2 & - & - & 1.03 \\
\hline & & & & Mean & 0.93 & 1.01 & 1.14 \\
\hline & & & & $\mathrm{COV}$ & 0.04 & 0.05 & 0.06 \\
\hline
\end{tabular}


The design approach is now presented in the framework of the EC3 [24] buckling curves, in which the imperfection parameter $\eta$ in Equation (11) is given as:

$$
\eta=\alpha(\bar{\lambda}-0.2)
$$

where $\alpha$ is an imperfection factor as specified in Table 6.2 of EC3 and

$$
\bar{\lambda}=\sqrt{\frac{A_{\mathrm{t}} f_{\mathrm{ty}}}{N_{\mathrm{cr}}}},
$$

in which $N_{\text {cr }}$ is the elastic buckling load of the column and $L_{\mathrm{cr}}$ is the effective length of the cable-in-tube system. Utilising the imperfection factor of Equation (15) with Equation (11), the compressive resistance, $N_{\mathrm{u} \text {,calc }}$, of a prestressed cable-in-tube system may be expressed as:

$$
N_{\mathrm{u}, \mathrm{calc}}=\chi_{\mathrm{p}} N_{\mathrm{pl}}
$$

where $N_{\mathrm{pl}}=A_{\mathrm{t}} f_{\mathrm{ty}}$ and

$$
\chi_{\mathrm{p}}=\frac{\left(1-\frac{P_{\mathrm{i}}}{N_{\mathrm{pl}}}\right)}{\alpha_{\mathrm{k}}\left[\phi_{\mathrm{p}}+\sqrt{\phi_{\mathrm{p}}^{2}-\frac{\left(1-\frac{P_{\mathrm{i}}}{N_{\mathrm{pl}}}\right)}{\alpha_{\mathrm{k}}} \bar{\lambda}^{2}}\right]}
$$

with

$$
\phi_{\mathrm{p}}=\frac{\left(1-\frac{P_{\mathrm{i}}}{N_{\mathrm{pl}}}\right) \bar{\lambda}^{2}+\left(\alpha_{\mathrm{k}}+\eta\right)}{2 \alpha_{\mathrm{k}}},
$$

where $\alpha_{\mathrm{k}}$ is defined in Equation (12).

The compressive capacity of grouted cable-in-tube systems can also be calculated using Equation (17), but the cross-section capacity and member slenderness should be redefined, as set out in EC4 [25], to account for the grout. The cross-section capacity $N_{\mathrm{pl,g}}$ and member slenderness $\bar{\lambda}_{\mathrm{g}}$ for the grouted members are given by Equations (20) and (21) respectively.

$$
\begin{gathered}
N_{\mathrm{pl}, \mathrm{g}}=A_{\mathrm{t}} f_{\mathrm{ty}}+A_{\mathrm{g}} f_{\mathrm{gk}}, \\
\bar{\lambda}_{\mathrm{g}}=\frac{L_{\mathrm{cr}}}{\pi} \sqrt{\frac{N_{\mathrm{pl}}}{E_{\mathrm{t}} I_{\mathrm{t}}+0.6 E_{\mathrm{gm}} I_{\mathrm{g}}}},
\end{gathered}
$$

where $A_{\mathrm{g}}$ and $f_{\mathrm{gk}}$ are the cross-sectional area and the characteristic compressive cylinder strength of the grout respectively, while $E_{\mathrm{gm}}$ and $I_{\mathrm{g}}$ are the secant modulus and the second moment of area of the grout respectively. Moreover, to incorporate the influence of the axial stiffness of the grout, $K_{\mathrm{g}}$, on the level of prestress during loading, a similar approach as in Section 2.3 is taken to redefine the constant $\alpha_{\mathrm{k}}$ thus:

$$
\alpha_{\mathrm{k}, \mathrm{g}} \begin{cases}=\frac{K_{\mathrm{t}}+K_{\mathrm{g}}}{K_{\mathrm{c}}+K_{\mathrm{t}}+K_{\mathrm{g}}}, & \text { if } P_{\mathrm{i}}>0, \\ =1, & \text { if } P_{\mathrm{i}}=0,\end{cases}
$$

where $K_{\mathrm{g}}=A_{\mathrm{g}} E_{\mathrm{gm}} / L_{\mathrm{o}}$. 


\subsubsection{Comparison of design capacity predictions with test and $3 D$ FE results}

In this section, the Perry-Robertson based design approach described above is assessed against the test results, as well as additional parametric results generated using the 3D FE model, validation of which was described in Sections 4.2 and 4.3. The measured cross-section geometry and material properties of the test specimens were employed throughout the parametric study, while the column length (and hence the slenderness) and the prestress level were the two key variables. A total of 24 parametric models were generated, as summarised in Table 10. All models had a global imperfection amplitude of $L_{0} / 1000$. In addition, 12 comparative results, using an elastic, perfectly plastic material model with $f_{\text {ty }}$ set equal to the $0.2 \%$ proof stress, were created to asses the influence of material nonlinearity (i.e. the rounded nature of the stress-strain curve associated with cold-formed material) on the response of prestressed steel columns. Comparisons between the latter results and the modified Perry-Robertson curves derived in Section 2.3 are shown in Figure 21, revealing very accurate agreement.

Next, comparisons between the test and parametric FE results with the measured (rounded) stress-strain curve, and the modified EC3 design curves described in Section 4.4.1, are shown in Figures 22 and 23 for non-grouted and grouted specimens, respectively. Initially buckling curve $\mathrm{c}$ was chosen, since this would be normally applied for the design of cold-formed hollow section compression members. For the lower prestress levels, the modified EC3 approach may be seen to provide good predictions of the test and FE capacities, but for higher prestress levels, unconservative predictions arise using curve c. This is attributed to the rounded nature of the stress-strain response, which effectively becomes more rounded with increasing prestress, since a greater portion of the linear range is consumed prior to the application of the external load. It is therefore proposed to use curve $\mathrm{c}$ for low service levels $\left(P \leq 0.25 N_{\text {ty }}\right)$ and curve $\mathrm{d}$ for higher prestress $\left(P>0.25 N_{\text {ty }}\right)$. Numerical comparisons between the design capacities determined on this bases and the test/FE results are shown in Table 8 and 9 for non-grouted and grouted elements respectively. Overall, consistent and generally safe-side capacity predictions are achieved. For hot-finished elements, it is anticipated that curve a would be applied and that no change in buckling curve would be required for higher prestress levels owing to the sharply defined yield point associated with hot-finished material.

\section{Conclusions}

The compressive behaviour of prestressed steel cable-in-tube systems has been examined in this study. Previous research has shown the benefit of the addition of prestressed cables to the tensile performance of these elements, but under load reversal, the presence of prestress can become detrimental. First, the purely axial response of the cable-in-tube system was analysed to investigate the load sharing between the two key components (tube and cable) and the optimum level of prestress to maximise the elastic range under external compressive loading. The member buckling response was then examined analytically, and it was shown that a modified Perry-Robertson approach, making due allowance for the presence of the prestress, provided an accurate representation of the physical behaviour of the system. This was subsequently developed into a design approach, based on the European buckling curves. 
Table 10: Summary of key properties of 3D FE models for parametric study.

\begin{tabular}{lccccc}
\hline Model & $\begin{array}{c}\text { Length } \\
(\mathrm{mm})\end{array}$ & $\begin{array}{c}\text { Grout } \\
(\mathrm{Y} / \mathrm{N})\end{array}$ & $\begin{array}{c}\text { Prestress } \\
(\mathrm{kN})\end{array}$ & $\bar{\lambda}$ & $\bar{\lambda}_{\mathrm{g}}$ \\
\hline C-0.8-NG-6-FE & 844 & $\mathrm{~N}$ & 6 & 0.5 & - \\
C-0.8-NG-60-FE & 844 & $\mathrm{~N}$ & 60 & 0.5 & - \\
C-0.8-NG-122-FE & 844 & $\mathrm{~N}$ & 122 & 0.5 & - \\
C-1.7-NG-6-FE & 1689 & $\mathrm{~N}$ & 6 & 1 & - \\
C-1.7-NG-60-FE & 1689 & $\mathrm{~N}$ & 60 & 1 & - \\
C-1.7-NG-122-FE & 1689 & $\mathrm{~N}$ & 122 & 1 & - \\
C-2.5-NG-6-FE & 2533 & $\mathrm{~N}$ & 6 & 1.5 & - \\
C-2.5-NG-60-FE & 2533 & $\mathrm{~N}$ & 60 & 1.5 & - \\
C-2.5-NG-122-FE & 2533 & $\mathrm{~N}$ & 122 & 1.5 & - \\
C-3.4-NG-6-FE & 3378 & $\mathrm{~N}$ & 6 & 2 & - \\
C-3.4-NG-60-FE & 3378 & $\mathrm{~N}$ & 60 & 2 & - \\
C-3.4-NG-122-FE & 3378 & $\mathrm{~N}$ & 122 & 2 & - \\
\hline C-0.8-G-11-FE & 765 & $\mathrm{Y}$ & 11 & - & 0.5 \\
C-0.8-G-90-FE & 765 & $\mathrm{Y}$ & 90 & - & 0.5 \\
C-0.8-G-126-FE & 765 & $\mathrm{Y}$ & 126 & - & 0.5 \\
C-1.5-G-11-FE & 1531 & $\mathrm{Y}$ & 11 & - & 1 \\
C-1.5-G-90-FE & 1531 & $\mathrm{Y}$ & 90 & - & 1 \\
C-1.5-G-126-FE & 1531 & $\mathrm{Y}$ & 126 & - & 1 \\
C-2.3-G-11-FE & 2296 & $\mathrm{Y}$ & 11 & - & 1.5 \\
C-2.3-G-90-FE & 2296 & $\mathrm{Y}$ & 90 & - & 1.5 \\
C-2.3-G-126-FE & 2296 & $\mathrm{Y}$ & 126 & - & 1.5 \\
C-3.1-G-11-FE & 3062 & $\mathrm{Y}$ & 11 & - & 2 \\
C-3.1-G-90-FE & 3062 & $\mathrm{Y}$ & 90 & - & 2 \\
C-3.1-G-126-FE & 3062 & $\mathrm{Y}$ & 126 & - & 2 \\
\hline
\end{tabular}




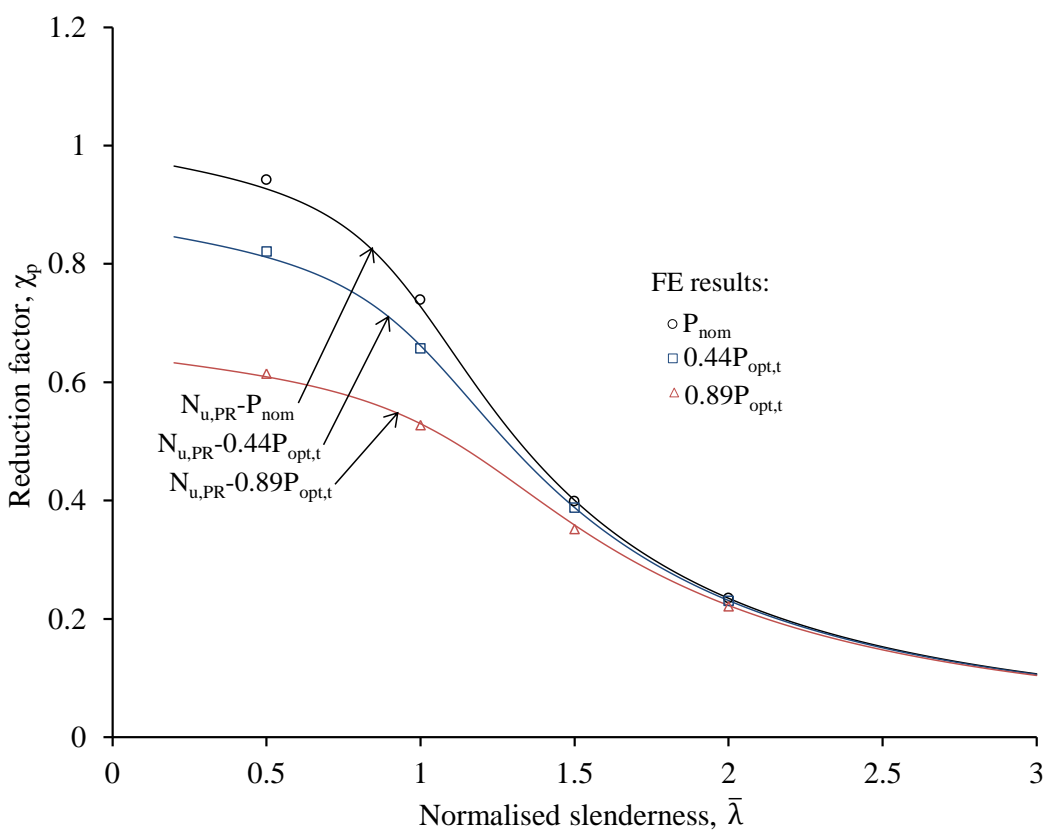

Figure 21: Comparison between modified Perry-Robertson compression capacities and 3D FE results for nongrouted prestressed elements with an elastic-perfectly-plastic material model.

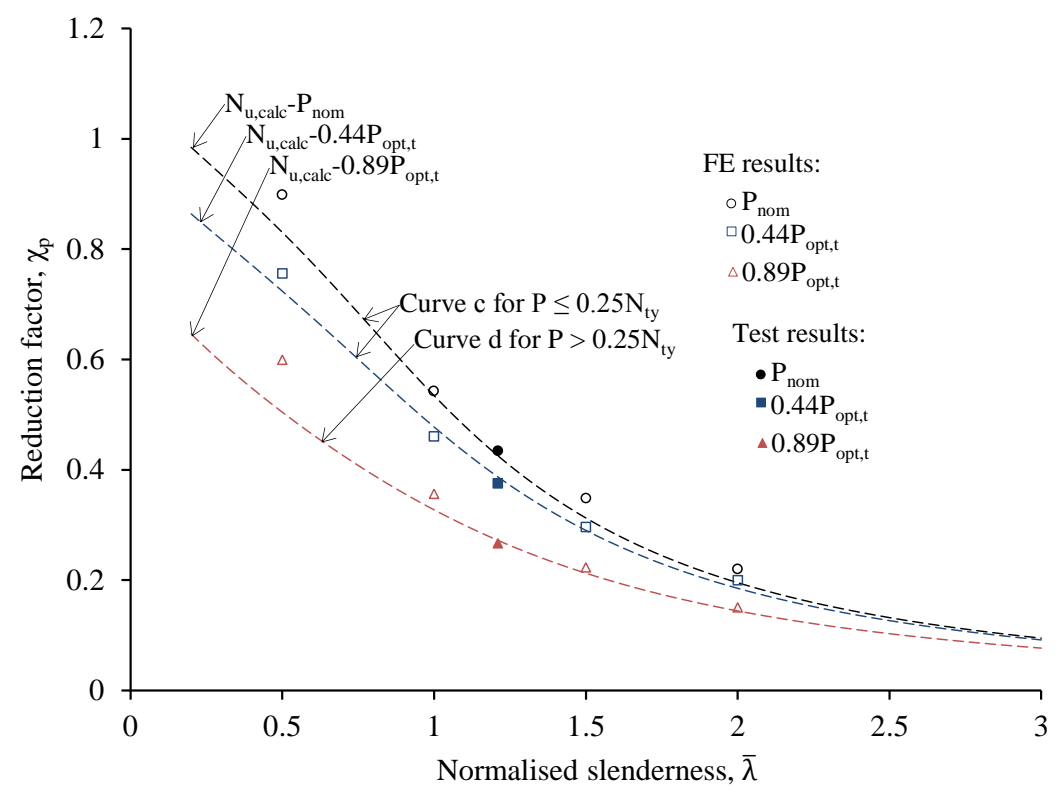

Figure 22: Comparison between calculated compression capacities, based on modified EC3 buckling curves for non-grouted prestressed elements with the material model described in Section 4.1.2. 


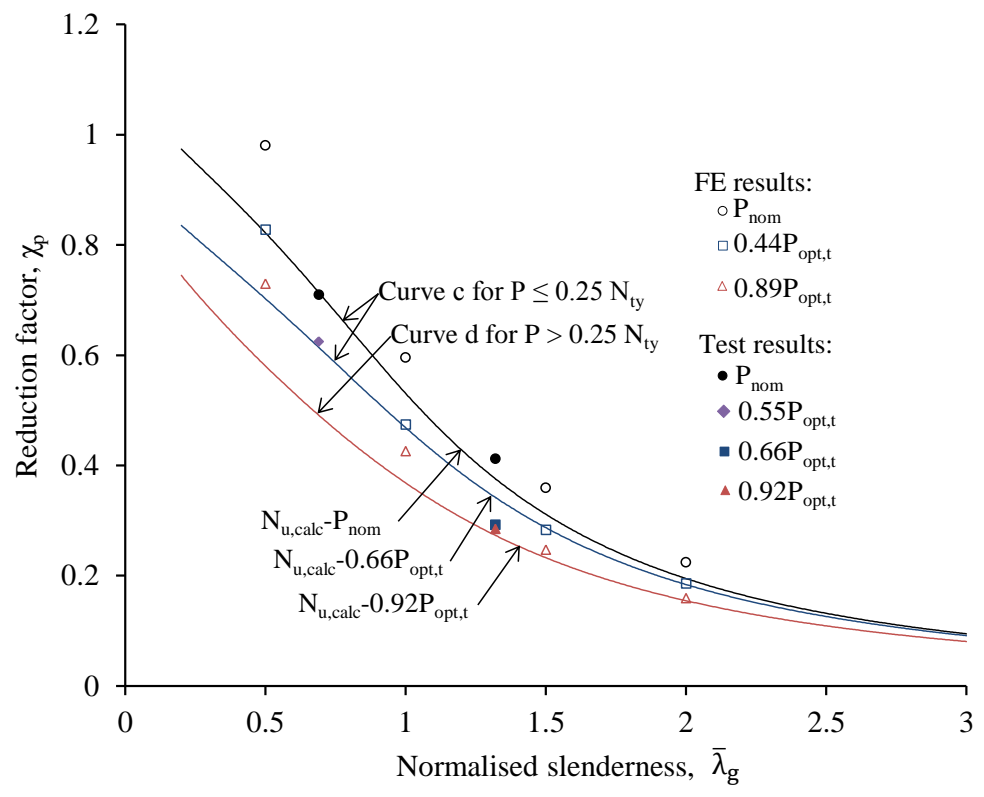

Figure 23: Comparison between calculated compression capacities, based on modified EC3 buckling curves for grouted prestressed elements with the material model described in Section 4.1.2.

A total of eight experiments to examine the compressive behaviour of prestressed cable-intube systems, featuring both non-grouted and grouted members, was performed. The measured geometric and material properties of the test specimens were reported, along with the full loaddeformation histories of the test specimens. Increasing initial prestress levels was found to reduce the capacity of the system in compression, but initial prestress was shown to be less detrimental than externally applied compressive loading of the same magnitude, due to the absence of second order bending moments (i.e. the line of action of the prestress remains along the centroidal axis of the member even in the deformed configuration). The presence of grout was shown, as expected, to increase the compressive capacity.

3D FE models were validated against the test results, shown to be capable of accurately capturing the observed physical behaviour, and then used to generate parametric results for a range of member slendernesses and prestress levels. The test and FE results were compared against capacity predictions based on a proposed modified Perry-Robertson design method. Consistent, accurate and generally safe-side predictions were achieved.

\section{Acknowledgements}

The authors are grateful to $S^{2}$ Space Solutions for their financial and technical contributions to the project, and would also like to thank the Structures Laboratory technicians at Imperial College London. 


\section{References}

\section{References}

[1] Magnel, G.. Prestressed steel structures. The Structural Engineer 1950;28:285-295.

[2] Belletti, B., Gasperi, A.. Behaviour of prestressed steel beams. Journal of Structural Engineering ASCE 2010;136(9):1131-1139.

[3] Madrazo-Aguirre, F., Ruiz-Teran, A.M., Wadee, M.A.. Dynamic behaviour of steelconcrete composite under-deck cable-stayed bridges under the action of moving loads. Engineering Structures 2014 [Submitted];

[4] Saito, D., Wadee, M.A.. Post-buckling behaviour of prestressed steel stayed columns. Engineering Structures 2008;30:1224-1239.

[5] Saito, D., Wadee, M.A.. Buckling behaviour of prestressed steel stayed columns with imperfections and stress limitation. Engineering Structures 2009;31:1-15.

[6] Saito, D., Wadee, M.A.. Numerical studies of interactive buckling in prestressed steel stayed columns. Engineering Structures 2009;31:432-443.

[7] Saito, D., Wadee, M.A.. Optimal prestressing and configuration of stayed columns. Proceedings of the Institution of Civil Engineers-Structures and Buildings 2010;163:343-355.

[8] Osofero, A.I., Wadee, M.A., Gardner, L.. Experimental study of critical and postbuckling behaviour of prestressed stayed columns. Journal of Constructional Steel Research 2012;79:226-241.

[9] Wadee, M.A., Gardner, L., Osofero, A.I.. Design of prestressed stayed columns. Journal of Constructional Steel Research 2013;80:82-90.

[10] Ayyub, B.M., Ibrahim, A.. Post-tensioned trusses: reliability and redundancy. Journal of Structural Engineering, ASCE 1990;116(6):1507-1521.

[11] Han, K.B., Park, S.K.. Parametric study of truss bridges by the post-tensioning method. Canadian Journal of Civil Engineering 2005;32:420-429.

[12] Li, H., Schmidt, L.. Post-tensioned and shaped hypar space trusses. Journal of Structural Engineering, ASCE 1997;123(2):130-137.

[13] Schmidt, L.C., Li, H.. Studies on post-tensioned and shaped space-truss domes. Structural Engineering and Mechanics 1998;6:693-710.

[14] Kyoungsoo, L., Ziaul, H., SangEul, H.. Analysis of stabilizing process for stress-erection of strarch frame. Engineering Structures 2013;59(2014):49-67. 
[15] Hancock, G.J., Key, P., Olsen, C.J.. Structural behaviour of a stressed arch structural system. In: Ninth International Specialty Conference on Cold-Formed Steel Structures. 1988, p. 557-569.

[16] Clarke, M.J., Hancock, G.J.. Finite-element nonlinear analysis of stressed-arch frames. Journal of Structural Engineering, ASCE 1991;117(10):2819-2837.

[17] Clarke, M.J., Hancock, G.J.. Simple design procedure for cold-formed tubular top chord of stressed-arch frames. Engineering Structures 1994;16(5):377-385.

[18] Clarke, M.J., Hancock, G.J.. Tests and nonlinear analysis of small-scale stressed-arch frames. Journal of Structural Engineering, ASCE 1995;121(2):187-200.

[19] Ellen, M.E., Gosaye, J., Gardner, L., Wadee, M.A.. Design and construction of longspan post-tensioned tubular steel structures. In: Gardner, L., editor. Tubular structures XIV. 2012, p. 687-693.

[20] Gosaye, J., Gardner, L., Wadee, M., Ellen, M.. Tensile performance of prestressed steel elements. Engineering Structures 2014;79:234-243.

[21] Bourne, S.. Prestressing: recovery of the lost art. The Structural Engineer 2013;91:12-22.

[22] Dassault Systemes Simulia Corp, . ABAQUS/standard: User's manual version 6.6. Hibbitt, Karlsson \& Sorensen, Inc.; Pawtucket, USA; 2006.

[23] Ayrton, W., Perry, J.. On struts. The Engineer (London) 1886;62:464-465.

[24] EN 1993-1-1:2005, . Eurocode 3: Design of steel structures - Part 1-1 : General rules and rules for buildings. Brussels: European committee for standardization (CEN); 2005.

[25] EN 1994-1-1:2004, . Eurocode 4: Design of composite steel and concrete structures Part 11: General rules and rules for buildings. Brussels: European committee for standardization (CEN); 2004.

[26] Afshan, S., Rossi, B., Gardner, L.. Strength enhancements in cold-formed structural sections - part I: Material testing. Journal of Constructional Steel Research 2013;83:177188.

[27] Ellobody, E., Young, B., Lam, D.. Behaviour of normal and high strength concretefilled compact steel tube circular stub columns. Journal of Constructional Steel Research 2006;62(7):706-716.

[28] Key, P., Hancock, G.. A theoretical investigation of column behaviour of cold-formed square hollow sections. Thin-Walled Structures 1993;16:31-64.

[29] Cruise, R.B., Gardner, L.. Residual stress analysis of structural stainless steel sections. Journal of Constructional Steel Research 2008;64(3):352-366. 
[30] Jandera, M., Gardner, L., Machacek, J.. Residual stresses in cold-rolled stainless steel hollow sections. Journal of Constructional Steel Research 2008;64(11):1255-1263.

[31] Mander, J., Priestley, M., Park, R.. Theoretical stressstrain model for con?ned concrete. Journal of Structural Engineering, ASCE 1988;114(8):1804-26.

[32] Hsuan-Tech, H., Chiung-Shiann, H., Ming-Hsien, W., Yih-Min, W.. Nonlinear analysis of axially loaded concrete-filled tube columns with confinement effect. Journal of Structural Engineering, ASCE 2003;129:10:1322-1329.

[33] Ellobody, E.. Numerical modelling of fibre reinforced concrete-filled stainless steel tubular columns. Thin-Walled Structures 2012;63:1-12.

[34] EN 1992-1-1:2004, . Eurocode 2: Design of concrete structures - Part 1-1 : General rules and rules for buildings. Brussels: European committee for standardization (CEN); 2004.

[35] CEB, . RC elements under cyclic loading. Tech. Rep.; Comite Euro-International Du Beton (CEB); 1996. 